\title{
Foxg1 Has an Essential Role in Postnatal Development of the Dentate Gyrus
}

\author{
Chuanxi Tian (田传熙), ${ }^{1 \star}$ Yifan Gong (宫一凡), ${ }^{1 \star}$ Ying Yang (杨颖), ${ }^{1}$ Wei Shen $\left(\right.$ 沈炜), ${ }^{1}$ Kun Wang (王焜), \\ Junhua Liu (刘俊华), ${ }^{1,2}$ Bokai Xu (许伯凯), ${ }^{1}$ Jing Zhao (赵静), ${ }^{3}$ and Chunjie Zhao (赵春杰) $)^{1}$ \\ ${ }^{1}$ Key Laboratory of Developmental Genes and Human Diseases, Ministry of Education, Institute of Life Science, Southeast University, Nanjing 210009 , \\ China, ${ }^{2}$ Department of Human Anatomy and Histoembryology, Medical School, Southeast University, Nanjing 210009, China, and ${ }^{3}$ Key Laboratory of \\ Model Animal for Disease Study, Ministry of Education, Model Animal Research Center, Nanjing University, Nanjing 210061, China
}

Foxg1, formerly BF-1, is expressed continuously in the postnatal and adult hippocampal dentate gyrus (DG). This transcription factor (TF) is thought to be involved in Rett syndrome, which is characterized by reduced hippocampus size, indicating its important role in hippocampal development. Due to the perinatal death of Foxg $1^{-1-}$ mice, the function of Foxgl in postnatal DG neurogenesis remains to be explored. Here, we describe the generation of a Foxg $1^{\mathrm{f} / \mathrm{fl}}$ mouse line. Foxg1 was conditionally ablated from the DG during prenatal and postnatal development by crossing this line with a Frizzled9-CreER ${ }^{\mathrm{TM}}$ line and inducing recombination with tamoxifen. In this study, we first show that disruption of Foxg1 results in the loss of the subgranular zone and a severely disrupted secondary radial glial scaffold, leading to the impaired migration of granule cells. Moreover, detailed analysis reveals that Foxg1 may be necessary for the maintenance of the DG progenitor pool and that the lack of Foxg1 promotes both gliogenesis and neurogenesis. We additionally show that Foxg1 may be required for the survival and maturation of postmitotic neurons and that Foxg1 may be involved in Reelin signaling in regulating postnatal DG development. Last, prenatal deletion of Foxg1 suggests that it is rarely involved in the migration of primordial granule cells. In summary, we report that Foxg1 is critical for DG formation, especially during early postnatal stage.

\section{Introduction}

In mammals, neurogenesis occurs in the subgranular zone (SGZ) of the dentate gyrus (DG) throughout adulthood (Leutgeb et al., 2007; Bakker et al., 2008; Deng et al., 2010). Research suggests that the continuous generation of DG neurons is involved in the acquisition of new memories (Van Dijck et al., 2000; Aimone et al., 2006) and in the behavioral effects of neuropathy (Gu et al., 2011; Surget et al., 2011; Zhang and Luo, 2011).

The formation of the DG is a complex process involving cell migration and neuronal differentiation (Pleasure et al., 2000; Li and Pleasure, 2005). Factors that regulate early DG development are thought to have similar functions in adult neurogenesis, although the molecular mechanisms underlying neurogenesis in the DG are not fully understood. A cascade of transcriptional events controls the specification of neuronal identity in the DG (Deng et al., 2009, 2010; Jessberger et al., 2009), but details of the expression pattern and function of each transcription factor (TF)

Received Oct. 17, 2011; revised Dec. 14, 2011; accepted Dec. 21, 2011.

Author contributions: C.T., Y.G., and C.Z. designed research; C.T., Y.G., Y.Y., W.S., K.W., J.L., and B.X. performed research; J.Z. contributed unpublished reagents/analytic tools; Y.G. analyzed data; Y.G. and C.Z. wrote the paper.

This work was supported by funds from the National Nature Science Foundation of China (Grant 30525017), from the Ministry of Science and Technology of China (Grants 2007(B12300), and from the National Nature Science Foundation of China (Grants 81070904 and 31171040) to C.Z. We thank Yiquan Wei, Li Liu, and Yang Yang for laboratory and animal care assistance.

${ }^{*}$ C.T. and Y.G. contributed equally to this work.

Correspondence should be addressed to Chunjie Zhao, Key Laboratory of Developmental Genes and Human Diseases, Ministry of Education, Institute of Life Science, Southeast University, 87 Dingjiaoqiao Road, Nanjing 210009, China. E-mail: zhaocj@seu.edu.cn.

DOI:10.1523/JNEUROSCI.5240-11.2012

Copyright $\odot 2012$ the authors $\quad 0270-6474 / 12 / 322931-19 \$ 15.00 / 0$ remain elusive. Foxg1 (formerly $B F-1$ ) encodes a forkhead family TF expressed primarily in the telencephalon (Tao and Lai, 1992). Analyses of mice lacking Foxg1 provided early evidence that this gene is a key regulator of neurogenesis (Xuan et al., 1995). In the cerebral cortex, the loss of Foxg1 results in premature cell cycle exit and the neuronal differentiation of neocortical neural progenitors (Xuan et al., 1995; Hanashima et al., 2002). Furthermore, it has been shown that $92 \%$ of patients with mutations in Foxg1 suffer from the congenital form of Rett syndrome, which results in postnatal microcephaly, severe mental retardation, the absence of language, dyskinesia, and corpus callosum hypogenesis (Ariani et al., 2008; Mencarelli et al., 2010; Kortüm et al., 2011). Because mental disorders are usually linked to abnormal neurogenesis ( $\mathrm{Gu}$ et al., 2011; Surget et al., 2011; Zhang and Luo, 2011), the involvement of Foxg1 in these diseases indicates a potential role for this gene in neurogenesis, especially in the DG.

Due to the perinatal lethality of Foxg $1^{-1-}$ mice (Xuan et al., 1995; Hanashima et al., 2002), the function of Foxg1 in postnatal DG neurogenesis has not been explored. To elucidate its role in postnatal DG development, we generated a Foxg $1{ }^{\mathrm{fl} / \mathrm{fl}}$ mouse line and a tamoxifen (TM)-inducible Cre line, Frizzled9-CreER ${ }^{\mathrm{TM}}$. Cre-mediated recombination is strong in the hippocampal primordium and its derivatives at embryonic stages in Frizzled9CreER $^{\mathrm{TM}}$ mice. Between postnatal day 2 (P2) and adulthood, recombinant activity is widespread in the DG, making this line a useful tool for the study of DG development and adult neurogenesis (Li et al., 2011). Through TM induction in Frizzled9-Cre$\mathrm{ER}^{\mathrm{TM}} ;$ Foxg $1^{\mathrm{fl} / \mathrm{fl}}$ crosses, Foxg1 was conditionally deleted during 
DG development. Our results indicate that Foxg1 is critical for DG development and may be involved in Reelin signaling in regulating postnatal DG development.

\section{Materials and Methods}

Animals. For the generation of Foxg $1^{\mathrm{f} / \mathrm{fl}}$ mice, the targeting vector (see Fig. 1a) includes the $5^{\prime}$ homology arm (576 bp), the 5' loxP site, the fragment containing the Foxg1 exon 1 and 2, the $3^{\prime}$ loxP site, a neomycinresistance cassette flanked by flippase recombinase target (FRT) sites, and the $3^{\prime}$ homology arm (453 bp). Clones were analyzed by PCR and Southern blotting (probe 1 for the $5^{\prime}$ end and probe 2 for the $3^{\prime}$ end; see Fig. 1a, dashed box above Foxg1 locus). In the wild-type Foxg1 locus, probe 1 hybridized to a $13.6 \mathrm{~kb}$ fragment and to a $9.6 \mathrm{~kb}$ fragment in the Foxg 1 loxp allele. Probe 2 hybridized to a $17.6 \mathrm{~kb}$ fragment in the wild type or to a $7.5 \mathrm{~kb}$ in the Foxg1 $1^{\text {loxp }}$ allele. Mice homozygous for Foxg1 alleles $\left(\right.$ Foxg $1^{\mathrm{fl} / \mathrm{fl}}$ ) were crossed with Foxg1 ${ }^{\mathrm{fl} / \mathrm{fl}}$ mice expressing the Cre recombinase transgene under the control of the Frizzled9 promoter ( $\mathrm{Li}$ et al., 2011). Cre-positive mice of either sex were treated with TM and examined. While Cre-negative animals of either sex, littermates when possible, were also treated with TM and used as controls. To examine the efficiency of TM-induced Cre-mediated recombination, Frizzled9-CreER ${ }^{\mathrm{TM}}$ mice were crossed with ROSA26-Cre reporter mice (Soriano, 1999). The Cre reporter line harbors a knock-in of a lac $Z$ gene preceded by a stop cassette, flanked by two recognition sequences (loxP) for the Cre recombinase, in the ROSA26 locus. Upon TM treatment, CreER translocates into the nucleus and deletes the stop cassette, thereby permitting $\beta$-galactosidase expression. All experimental procedures involving animals were performed in accordance with guidelines from the National Institutes of Health of China.

Mouse genotyping. Mutant mice were genotyped by PCR as follows. For Foxg $1^{\mathrm{fl} / \mathrm{fl}}$ mice, the oligos included the following: Foxg1-FRTtF2, 5'-ATA AAG ATT TGC TGA GTT GGA-3'; and Foxg1-FRTtR2, 5' -TGG AGG GGG AGA TAG GGC TAT- $3^{\prime}$. The program included $94^{\circ} \mathrm{C}$ for 5 $\min (1 \times) ; 94^{\circ} \mathrm{C}$ for $30 \mathrm{~s}, 58^{\circ} \mathrm{C}$ for $45 \mathrm{~s}$, and $72^{\circ} \mathrm{C}$ for $45 \mathrm{~s}(35 \times)$; and $72^{\circ} \mathrm{C}$ for $10 \mathrm{~min}(1 \times)$; the PCR products included $101 \mathrm{bp}$ (wild-type allele) and $2033 \mathrm{bp}$ (null allele). For reeler mice, the oligos included the following: Primer A, 5' -TAA TCT GTC CTC ACT CTG CC-3'; Primer $B$, 5' CAG TTG ACA TAC CTT AAT- $3^{\prime}$; and Primer $C, 5^{\prime}$-TGC ATT AAT GTG CAG TGT $-3^{\prime}$; the program included $94^{\circ} \mathrm{C}$ for $3 \mathrm{~min}(1 \times) ; 94^{\circ} \mathrm{C}$ for $45 \mathrm{~s}, 51^{\circ} \mathrm{C}$ for $90 \mathrm{~s}$, and $72^{\circ} \mathrm{C}$ for $1 \mathrm{~min}(30 \times)$; and $72^{\circ} \mathrm{C}$ for $10 \mathrm{~min}(1 \times)$; the PCR products included $266 \mathrm{bp}$ (reeler wild type, Primer $A$ with Primer $B$ ) and 363 bp (reeler mutant, Primer A with Primer C).

$B r d U$ injection. Mice were intraperitoneally injected with bromodeoxyuridine (BrdU, Sigma-Aldrich, B5002) dissolved in $1 \times$ PBS $(10 \mathrm{mg} /$ $\mathrm{ml}$ ) at the dose of $100 \mathrm{mg} / \mathrm{kg}$ for acute labeling or birthdating analysis.

Tamoxifen induction. TM (Sigma-Aldrich, T5648-5G) was dissolved in corn oil (Sigma-Aldrich, C8267) at $20 \mathrm{mg} / \mathrm{ml}$. For TM induction at embryonic stages, pregnant mice were dosed with $2 \mathrm{mg}$ of TM per $40 \mathrm{~g}$ of body weight by intraperitoneal injection. For TM induction at postnatal and adult stages, $2 \mathrm{mg}$ of TM per $40 \mathrm{~g}$ of body weight was administered by intraperitoneal injection.

Tissue preparation. Before tissue harvest, animals were deeply anesthetized with sodium pentobarbital $(40 \mathrm{mg} / \mathrm{kg}$, dissolved in physiological saline) through intraperitoneal injection. Animals older than embryonic day 13.5 were perfused intracardially with $0.1 \mathrm{M} \mathrm{PBS,} \mathrm{pH} \mathrm{7.4,} \mathrm{followed} \mathrm{by}$ $4 \%$ paraformaldehyde (PFA) in PBS. Brains were immersion-fixed in $4 \%$ PFA in $0.1 \mathrm{M}$ PBS for $6-8 \mathrm{~h}$ at $4^{\circ} \mathrm{C}$ before being processed for cryosectioning in $30 \%$ sucrose.

Hematoxylin and eosin staining assay. Sections were stained in hematoxylin for 5-15 $\mathrm{min}$, the excess stain solution on the slides was rinsed off, and color separation with $0.5-1 \%$ hydrochloride alcohol (made by $75 \%$ alcohol) was performed for $\sim 10 \mathrm{~s}$. After rinsing with running water for 15-30 $\mathrm{min}$, the tissues were stained by $0.1-0.5 \%$ eosin for $1-5 \mathrm{~min}$. Before being hyalinized with dimethylbenzene twice for $\sim 10 \mathrm{~min}$ in total, the tissues were dehydrated with $75 \%, 85 \%, 95 \%$, and $100 \%$ alcohol for 2-3 min in turn. As a last step, coverslips were applied.

$X$-gal staining. Embryos or embryonic brains were immersed into freshly prepared $2 \% \mathrm{PFA}$ at $4^{\circ} \mathrm{C}$ for $30 \mathrm{~min}$. Brains older than P0 were perfused by $2 \%$ PFA. Tissues were then cryoprotected in $30 \%$ sucrose, embedded in OCT, and cut into $40 \mu \mathrm{m}$ sections using a Leica cryostat. After washing and permeabilizing in PBS containing $0.02 \%$ NP-40 and 2 $\mathrm{mM} \mathrm{MgCl}_{2}$ for $30 \mathrm{~min}$, the tissue was stained with $1 \mathrm{mg} / \mathrm{ml} \mathrm{X-gal} \mathrm{in} \mathrm{PBS}$ containing $0.02 \% \mathrm{NP}-40,5 \mathrm{~mm} \mathrm{~K}_{3} \mathrm{Fe}(\mathrm{CN})_{6}, 5 \mathrm{~mm} \mathrm{~K}_{4} \mathrm{Fe}(\mathrm{CN})_{6}$, and $2 \mathrm{~mm}$ $\mathrm{MgCl}_{2}$ at $37^{\circ} \mathrm{C}$ for $\sim 16 \mathrm{~h}$. Sections were then rinsed with PBS, refixed in $4 \%$ PFA for $4 \mathrm{~h}$, and sealed with coverslips.

Selected markers for DG cell compartments. Primary progenitor cells (also referred to as type-1 cells) are usually characterized by GFAP or brain lipid binding protein (BLBP) expression (Hartfuss et al., 2001; Ganat et al., 2006; Anthony and Heinz, 2008; Heiman et al., 2008). These cells exhibit morphology typical of radial glia and divide slowly to produce intermediate progenitor cells (IPCs; also referred to as type-2 cells), a type of transit amplifying cell (Filippov et al., 2003; Holmes et al., 2004; Kempermann et al., 2004; Steiner et al., 2004; Englund et al., 2005). Undifferentiated IPCs (also referred to as type-2a and type-2b cells) express Mash1, Ngn2, and Tbr2 (Englund et al., 2005; Helms et al., 2005; Ozen et al., 2007; Elmi et al., 2010) and divide rapidly to produce neuronal committed IPCs (type-3) (Englund et al., 2005; Lie et al., 2005; Roybon et al., 2009; Bedogni et al., 2010). NeuroD1 expression marks the end of the transient amplifying progenitor phase. Upon NeuroD1 expression, progenitors exit the cell cycle, gradually mature, and express PSANCAM, NeuroD2, calretinin, prox1, Tbr1, and finally NeuN. GFAP and BLBP also label immature astroglial cells in the early postnatal DG. These immature astrocytes can be distinguished from neural stem cells (NSCs) by their morphology and outer location (Vodovnik, 2003; Sarthy, 2007; Ekmark-Lewén et al., 2010; Böhmer et al., 2011). Thus, we used GFAP and BLBP to label NSCs and astrocytes, Tbr2 to label IPCs, and calretinin and NeuN to label immature and mature neurons, respectively.

Immunohistochemistry. Sections were washed in PBS, blocked with $10 \%$ calf serum, permeabilized in PBS containing $0.1 \%$ Triton X-100 (PBT) for $2 \mathrm{~h}$, and incubated in primary antibody diluted in blocking solution overnight at $4^{\circ} \mathrm{C}$. Sections were subsequently washed in PBT, incubated in the secondary antibody for $2 \mathrm{~h}$ at $37^{\circ} \mathrm{C}$, and washed with PBS five times. As a last step, coverslips were applied. The following antibodies and reagents were used for immunostaining: rabbit antiBLBP (Abcam, AB32423, 1:1000); rabbit anti-calretinin (Millipore, AB5054, 1:2000); rabbit anti-Cre (Covance, PRB-106C, 1:1000); rabbit anti-caspase3 (Cell Signaling Technology, P42574, 1:500); rabbit antiFoxg1 (Abcam, AB18259, 1:100); rabbit anti-prox1 (Millipore, AB5475, 1:2000); rabbit anti-Tbr2 (Abcam, AB23345, 1:1000); rabbit antivimentin (Signalway Antibody, 21488, 1:2000); mouse anti-BrdU (Millipore, MAB3510, 1:3000); mouse anti-calretinin (Millipore, MAB1568, 1:500); mouse anti-GFAP (Millipore, MAB360, 1:500); mouse antiNeuN (Millipore, MAB377, 1:200); mouse anti-Ki67 (Leica, NCL-LKi67-MM1, 1:100); mouse anti-Reelin (Millipore, MAB5364, 1:3000); rat anti-BrdU (Abcam, Ab6326, 1:500); FITC goat anti-mouse IgG (Jackson ImmunoResearch, 115-095-146, 1:200); Alexa Fluor 555 donkey anti-mouse IgG (Invitrogen, A31570, 1:500); Alexa Fluor 633 goat antimouse IgG (Invitrogen, A21050, 1:500); Alexa Fluor 488/633 goat antirabbit IgG (Invitrogen, A11008/A21071, 1:500), Alexa Fluor 555 donkey anti-rabbit IgG (Invitrogen, A31572, 1:500); and Alexa Fluor 488 goat anti-rat IgG (Invitrogen, A11006, 1:500). DAPI was purchased from Sigma-Aldrich (D9564).

Cell counting. For cell counting, $18 \mu \mathrm{m}$ coronal hippocampal sections were examined in two to three comparative sections from the anterior to posterior levels in each brain by an experimenter blind to the animal genotype. The pictures used in cell counting were acquired using a FluoView FV1000 confocal microscopy (Olympus). Pictures were acquired with the $20 \times$ objective lens, and cells were counted in a minimum of three sections taken from each brain. To define the counting area, we used Image Pro Plus software (Media Cybernetics) to outline an area of interest containing the DG area (including the hilus, granular layer, and molecular layer) manually based on the DAPI staining.

Western blot. To evaluate FoxG1 expression, 14-d-old reeler and control mice were anesthetized and decapitated. The DGs were dissected out and homogenized on ice in protein lysis buffer containing the following: $1 \mathrm{M} \mathrm{MgCl}_{2}, 1 \mathrm{M}$ Tris, pH 7.5, $10 \mathrm{~mm}$ PMSF, and 10\% Nonidet P-40. Homogenates were centrifuged at 13,000 rpm for $15 \mathrm{~min}$ at $4^{\circ} \mathrm{C}$. Super- 
natants were stored at $-80^{\circ} \mathrm{C}$ until used. For Western blotting, equivalent amounts of protein from each sample $(50-100 \mu \mathrm{g})$ were resolved in $10 \%$ SDS-PAGE and transferred onto a nitrocellulose membrane. Membranes were blocked at room temperature for $60 \mathrm{~min}$ in 5\% nonfat dry milk in Tris-buffered saline-Tween 20 (TBST) (containing the following: $10 \mathrm{M}$ Tris- $\mathrm{HCl}$ buffer, $\mathrm{pH} 8.0,150 \mathrm{M} \mathrm{NaCl}$, and $0.1 \%$ Tween 20) and incubated overnight at $4^{\circ} \mathrm{C}$ with rabbit anti-Foxg1 antibody (1:500; Abcam, AB18259) in 5\% nonfat dry milk in TBST. Blots were washed three times in TBST and incubated with horseradish peroxidase-conjugated goat anti-rabbit secondary antibody (1:5000; Cell Signaling Technology, 7074 ) in 5\% nonfat dry milk in TBST. Bands were detected using enhanced chemiluminescence (Pierce Biotechnology, NCI5079). Blots were stripped and then reincubated for $1 \mathrm{~h}$ at room temperature with mouse anti- $\beta$-actin (1:5000; Sigma-Aldrich, $115 \mathrm{~K} 4825)$, washed, and incubated with horseradish peroxidase-conjugated goat anti-mouse secondary antibody (1:5000; Cell Signaling Technology, 7076) using the same procedure as above.

Quantitative real-time PCR. Total RNA from control and mutant DGs was isolated using the RNeasy Plus Mini Kit for RNA isolation (Qiagen, 74104) according to the manufacturer's instructions and each sample was reverse transcribed using Multiscribe reverse transcriptase (Fermentas, EP0441). The quantitative PCR reactions were performed using SYBR Green fluorescent master mix (Roche, 4913914001) on a StepOnePlus Real-Time PCR System (Applied Biosystems). Primers were designed and synthesized by Takara Bio as follows: Foxg1, forward, TGGCAACACTGCCCATTCA, reverse, GCATTTGCGCAACACAGGTTA; reelin, forward, CGGGCTCTGCGGACCAG, reverse, ACATCCAGGGCCAAGGTAGAA. Samples were run in triplicate and contained $1 \times$ SYBR Green master mix, $10 \mu \mathrm{M}$ each primer, and RNase-free water for a final volume of $20 \mu \mathrm{l}$. Samples without RNAs were run for each reaction as negative controls. The following cycles were performed: initial denaturation cycle of $95^{\circ} \mathrm{C}$ for $10 \mathrm{~min}$, followed by 40 amplification cycles of $95^{\circ} \mathrm{C}$ for $15 \mathrm{~s}$ and $58^{\circ} \mathrm{C}$ (Foxg 1 ) or $63^{\circ} \mathrm{C}$ (reelin) for $1 \mathrm{~min}$, and ending with one melt curve cycle of $95^{\circ} \mathrm{C}$ for $15 \mathrm{~s}$ and $60^{\circ} \mathrm{C}$ then $95^{\circ} \mathrm{C}$ for $15 \mathrm{~s}$. The relative gene expression between samples was normalized with the most reliable endogenous gene ( $\beta$-actin or GAPDH).

Statistical analysis. Student's $t$ tests were performed with Microsoft Excel to compare specific brain regions, absolute numbers, and relative percentages of cells. Each statistics group contained two to five brains from different litters (listed in detail in the legends of Figs. 1 and 4-9). Differences were considered significant at $p<0.05$.

\section{Results}

Lack of Foxg1 leads to developmental malformation of the postnatal dentate gyrus

Conventional knockouts of Foxg1 result in embryonic lethality (Xuan et al., 1995; Hanashima et al., 2002). For this reason, we used a conditional inactivation approach to evaluate the function of Foxg1 postnatally in the mammalian brain. Foxg1-floxed mice (Fig. 1a) were generated and mated to Frizzled9-CreER ${ }^{\mathrm{TM}}$ mice, allowing for conditional disruption upon Cre-mediated recombination. We first detected Cre expression in Frizzled9-CreER ${ }^{\mathrm{TM}}$ mice in the postnatal developing DG. Double immunofluorescent staining demonstrated that Cre was expressed not only in $\mathrm{GFAP}^{+}$NSCs (Fig. 1b) but also in calretinin ${ }^{+}$and $\mathrm{NeuN}^{+}$postmitotic neurons (Fig. 1c). To further characterize Cre activity, Frizzled9-CreER ${ }^{\mathrm{TM}}$ mice were crossed with a Rosa26-lac $Z$ reporter line. TM was injected at P5, and brains were harvested at P14. X-gal staining demonstrated strong recombination limited to the DG (Fig. 1d), with a sparse distribution of $\beta$-gal ${ }^{+}$cells in the cortex. $\beta$-Gal staining was also observed in the thalamus, the hypothalamus, and the amygdala (data not shown).

P5 is a critical age for DG development, and the following events occur in the DG at this time: (1) dispersed precursors gradually move toward the hilus and form the future precursor pool, the SGZ; (2) the primary radial glial scaffold gradually disappears, and the secondary radial glial scaffold forms; and (3) progenitors rapidly proliferate and generate granule cells. Newly formed granule cells then migrate along the secondary radial glial scaffold to the granular layer (GL). To assess the role of Foxg1 in postnatal neurogenesis in the DG and in the development of the secondary radial glial scaffold, Foxg1-floxed mice were crossed with the Frizzled9-CreER ${ }^{\mathrm{TM}}$ line. TM was given to these crosses at P5, and a $>90 \%$ loss of Foxg1 from the GL of DG was detected at P14 (Fig. 1e). The gross structures of the dorsal and ventral cortices and the thalamic nuclei were normal, as indicated by immunostaining for the neuronal marker NeuN (Fig. 1f). However, severe abnormalities were observed in the DG (Fig. $1 f, g$ ). Remarkably, there was a dramatic decrease in the size of the DG (Fig. $1 h$; from rostral to caudal, $p<0.008, p<1.4 \times 10^{-4}, p<$ 0.03 ). The formation of both the suprapyramidal and infrapyramidal blades of the DG was severely disrupted. The volume of the suprapyramidal blade was reduced (Fig. $1 \mathrm{~h}$; from rostral to caudal, $p<0.007, p<2.5 \times 10^{-4}, p<2.9 \times 10^{-5}$ ), and only a fraction of the infrapyramidal blade appeared (Fig. $1 \mathrm{~h}$; from rostral to caudal, $p<2.3 \times 10^{-4}, p<2.7 \times 10^{-4}, p<0.02$ ). Close examination of the abnormal DG revealed a dramatic decrease in the number of $\mathrm{NeuN}^{+}$granule cells (Fig. 1f).

\section{Foxg1 is critical for subgranular zone formation and granule cell migration}

The DG uses a distinct developmental strategy to produce a durable neurogenic niche (Li and Pleasure, 2005). Multipotential neural precursors seed the developing DG from their origin in the medial cortical neuroepithelium beginning at approximately midgestation. As the scaffolding of the DG forms at approximately the first postnatal week, precursors transit into the DG and settle in the SGZ at the border between the GL and the hilus. The SGZ provides a steady flow of newborn cells at postnatal stages. The decreased size and reduction in the number of $\mathrm{NeuN}^{+}$cells in mutant DGs suggested that the SGZ may be disrupted in Foxg1-ablated mice. Frizzled9-CreER ${ }^{\mathrm{TM}}$; Foxg $1^{\mathrm{t} / \mathrm{fl}}$ mice were therefore administered TM at P5, and brains were harvested at P7 following a $4 \mathrm{~h}$ BrdU pulse injection, which labels mitotic cells. There was a distinct reorganization of progenitors by $\mathrm{P} 7$ in control mice (Fig. $2 a$ ). $\mathrm{BrdU}^{+}$progenitors tended to cluster around the future SGZ and formed a condensed cell band. Additionally, migrating cells formed a stream and spread into the hilus (Fig. $2 a$, arrowheads). In mutant DGs, however, $\mathrm{BrdU}^{+}$cells were greatly reduced and scattered, and migrating cells were absent. To further characterize the distribution pattern of progenitors and their progenies, BrdU was administrated $24 \mathrm{~h}$ following P5 TM injections, and brains were harvested at P10. In control DGs, BrdU ${ }^{+}$ cells accumulated in the SGZ, while labeling revealed only sparse and scattered radially migrating $\mathrm{BrdU}^{+}$cells in the GL and molecular layer (ML) (Fig. 2b). The migration stream at this stage was even clearer than in $\mathrm{P} 7$ mice (Fig. $2 b$, arrowheads). In contrast, $\mathrm{BrdU}^{+}$ cells were remarkably reduced in mutant DGs, resulting in an absence of the SGZ. The cell migration stream to the hilus appeared to be blocked (Fig. $2 b$, arrow). Because BrdU pulse-labeled cells were mostly progenitors, we examined the distribution patterns of $\mathrm{Tbr}{ }^{+}$ and $\mathrm{GFAP}^{+}$progenitors. At P6, Tbr2 ${ }^{+}$IPCs were radially distributed from the hilus to the GL and finally resided in the SGZ (Fig. 2d). The condensed $\mathrm{Tbr} 2{ }^{+}$cell population separated into two bands, one in the DG marginal zone (MZ) and another in the SGZ (Fig. $2 d$, dashed lines). There were fewer Tbr2 ${ }^{+}$IPCs in mutants, and the cell band in the SGZ was absent (Fig. $2 d$, star). The MZ cell band, however, remained. In P14 control DGs, GFAP ${ }^{+}$radial glial cells and Tbr2 ${ }^{+}$IPCs were restricted to the SGZ (Fig. 2e). In mutant DGs, fewer $\mathrm{Tbr} 2^{+}$progenitors were observed in the SGZ, and some were ectopically distributed in the GL (Fig. $2 e$, arrowheads). In 
a
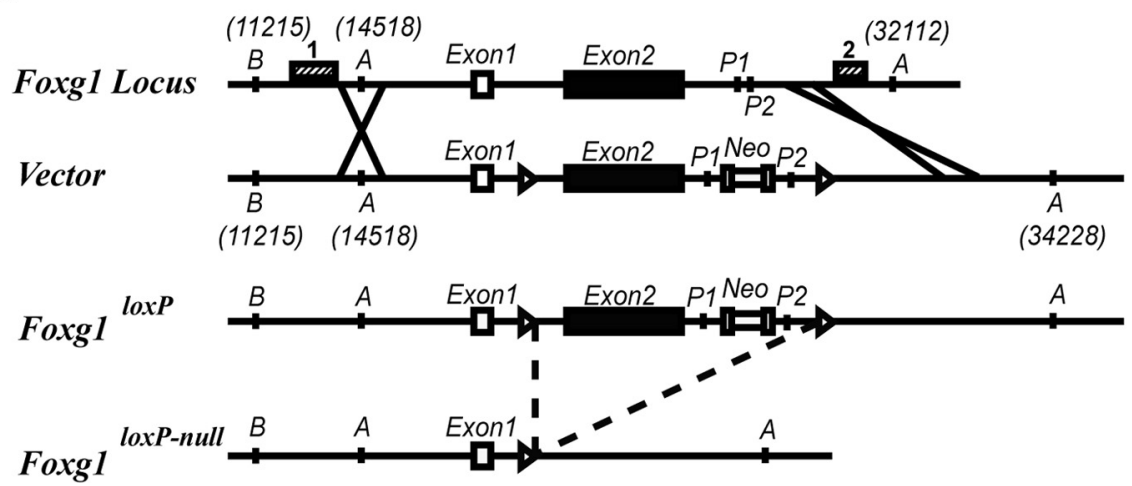

* A: Apoll B: BamHI D:LoxP site P1(Genotypying primer 1): FRTtF2 P2: FRTtR2
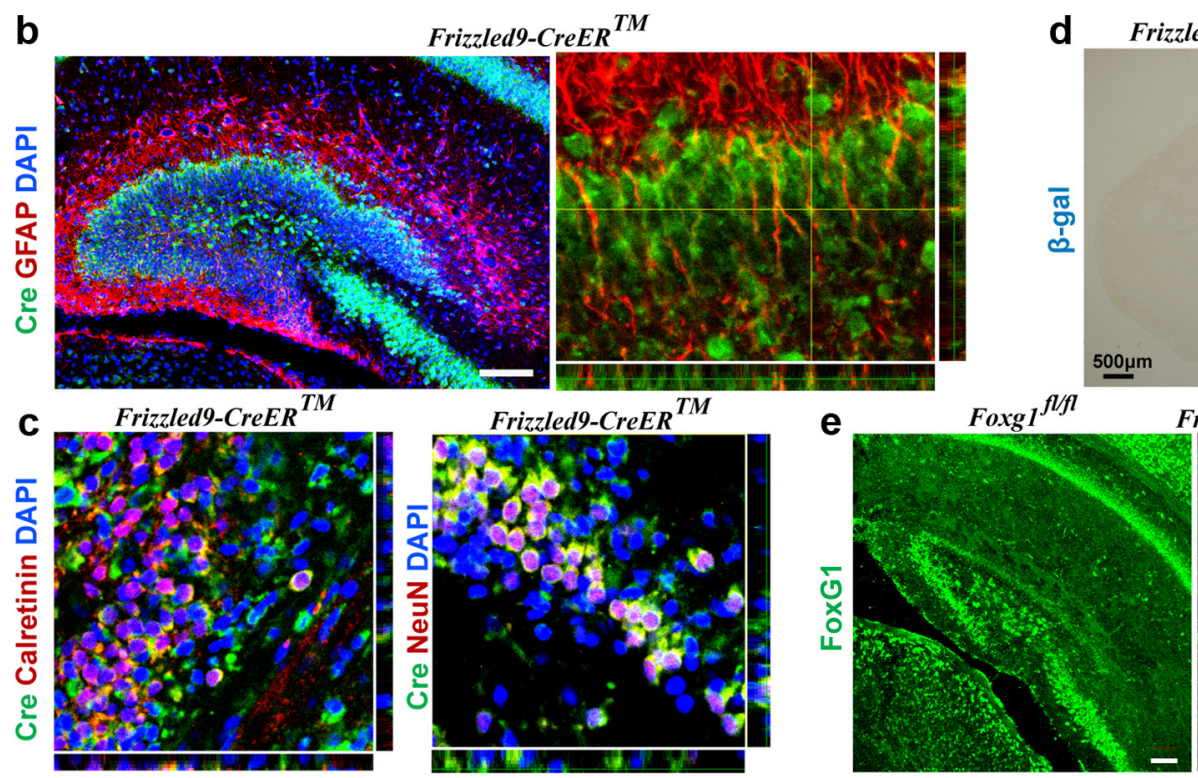

d Frizzled9-CreER ${ }^{T M} ;$ Rosa26-lacZ
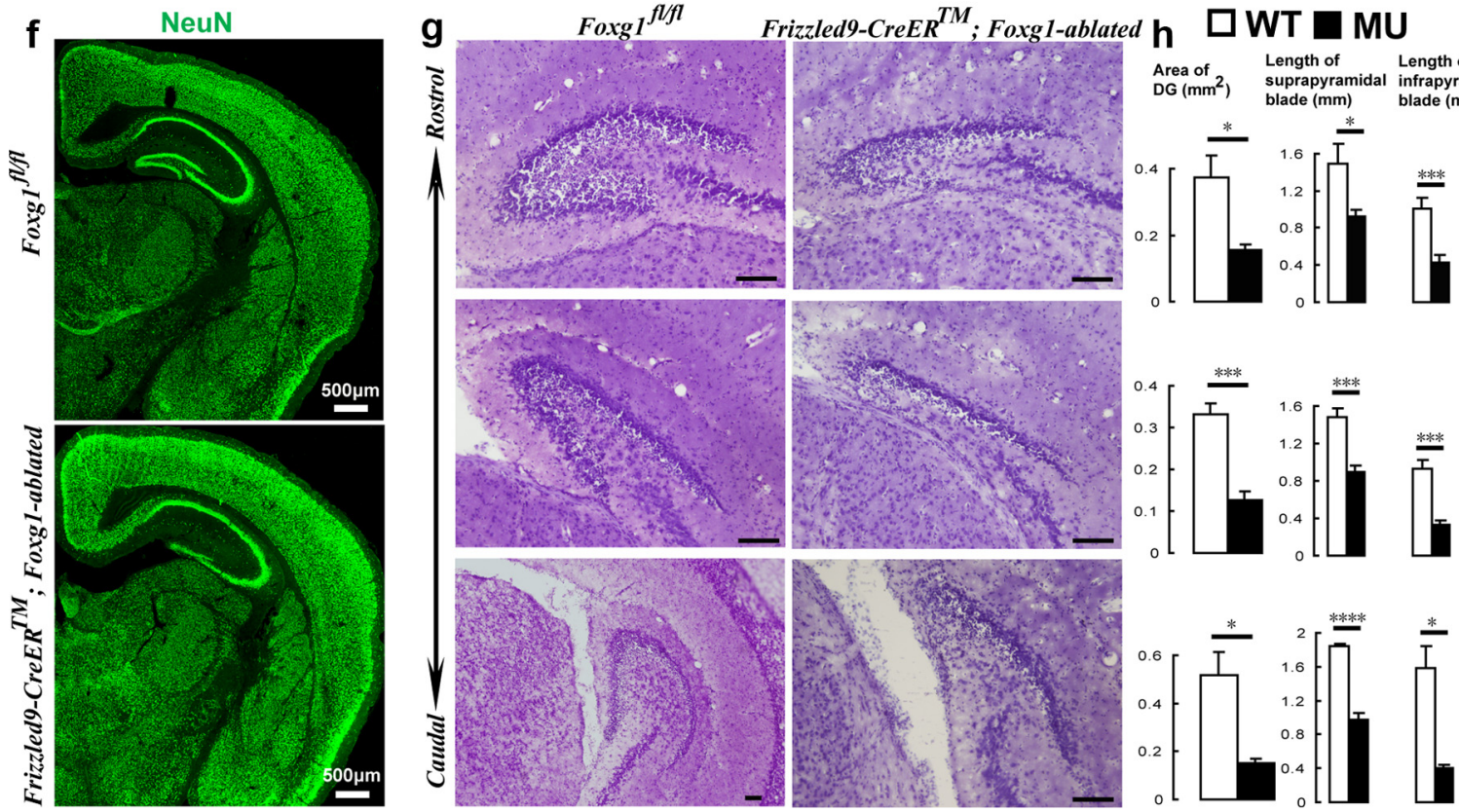

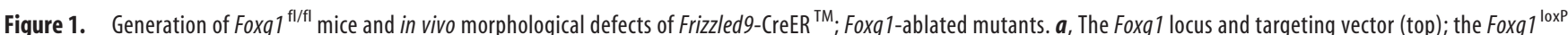
allele obtained by homologous recombination (middle); and the Foxg $1{ }^{\text {loxp-null }}$ allele resulting from Cre-mediated Foxg 1 excision (bottom). The dashed boxes above the Foxg 1 (Figurelegend continues.) 

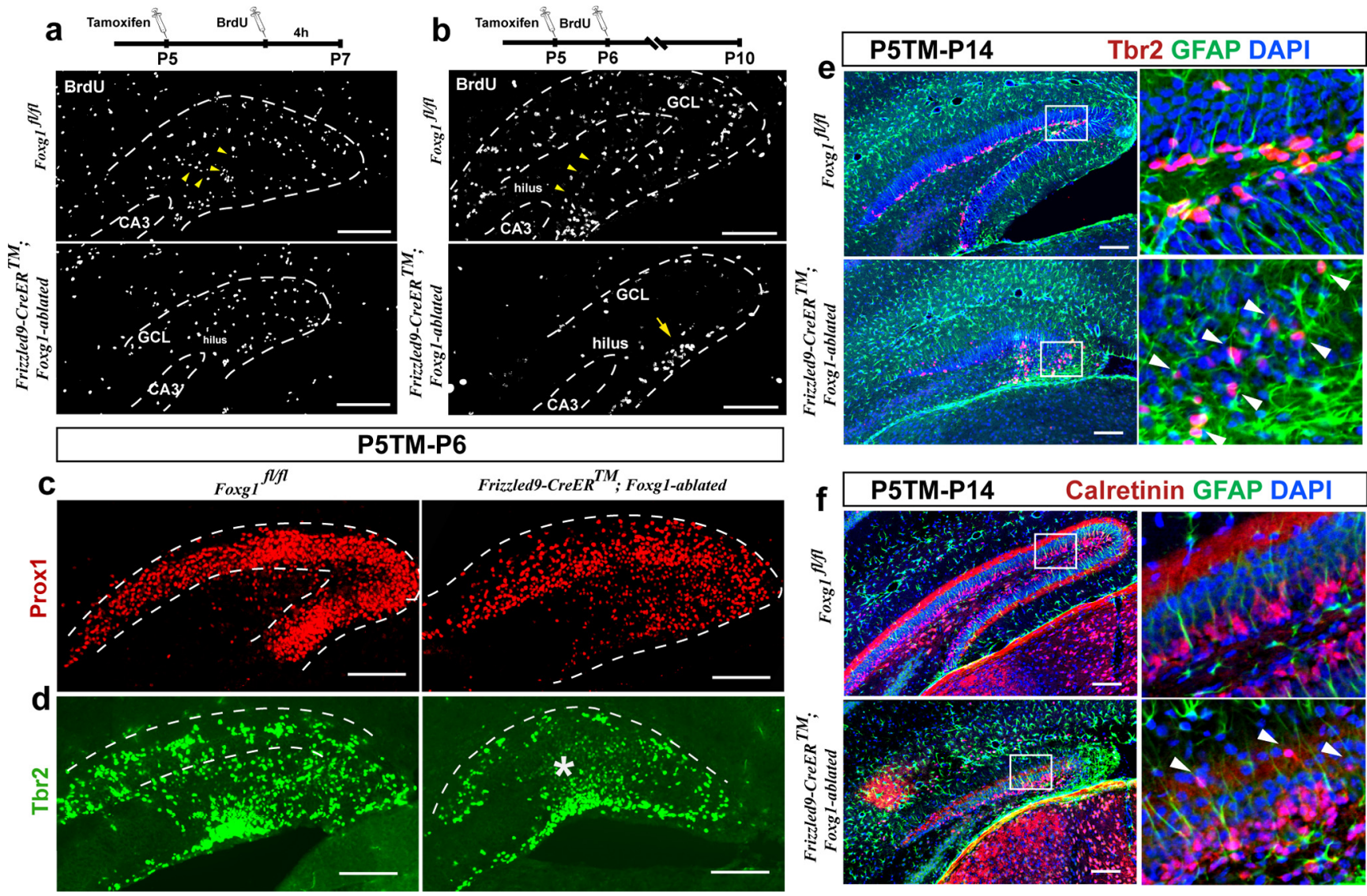

Figure 2. SGZ formation and granule cell migration disturbances in Frizzled9-CreER ${ }^{\mathrm{TM}} ;$ Foxg1-ablated mutants. Controls and Frizzledg-CreER ${ }^{\mathrm{TM}} ;$ Foxg ${ }^{\mathrm{f} / \mathrm{fl}}$ mice received TM treatment at P5. $\boldsymbol{a}$ Top, Schematic of TM and BrdU injections. Bottom, At P7 in controls, BrdU ${ }^{+}$progenitors (white) tended to surround the future SGZ and to form a condensed cell band. Yellow arrowheads indicate the migrating cell stream spreading into the hilus. In mutant DGs, BrdU ${ }^{+}$cells were greatly reduced in number and scattered, with migrating cells absent. $\boldsymbol{b}$, Top, Schematic of TM and BrdU injections. Bottom, At P10 in control DGs, BrdU ${ }^{+}$cells accumulated in the SGZ, while sparse staining in the GL and the ML indicated few radial migrating BrdU ${ }^{+}$cells. Yellow arrowheads indicate the migrating cell stream. In mutant $D G s$, the number of BrdU ${ }^{+}$cells was remarkably reduced, resulting in an absence of the $S G Z$. Yellow arrow shows the blocked migrating cells en route to the hilus. c, In P6 control DGs, prox ${ }^{+}$granule cells are densely packed to form the suprapyramidal and infrapyramidal blades. In mutant DGs, prox $1^{+}$cells are evenly distributed ectopically in the $G L$ and hilus. d, In P6 control DGs, Tbr2 ${ }^{+}$IPCs were radially distributed from the hilus to the $G L$ and resided in the SGZ. Dashed lines illustrate the two separated bands of Tbr2 ${ }^{+}$cells, one in the MZ of the DG and another in the SGZ. The star indicates a decreased number of Tbr2 ${ }^{+} \mathrm{IPCs}$ and an absent cell band in the SGZ of the mutant DG. $\boldsymbol{e}, \mathrm{In}$ P14 control DGs, GFAP ${ }^{+}$radial glial cells (green) and Tbr2 ${ }^{+}$IPCs (red) are restricted to the SGZ. In mutant DGS, GFAP ${ }^{+}$cells were in disarray, especially those in the infrapyramidal blade. Arrowheads indicate fewer Tbr2 ${ }^{+}$progenitors in the mutant SGZ, some of which were ectopically distributed in the GL.f In P14 control DGs, calretinin ${ }^{+}$immature neurons (red) are located within the inner sides of the suprapyramidal and infrapyramidal blades. In mutant DGs, these cells fail to migrate properly. Arrowheads indicate calretinin ${ }^{+}$cells ectopically located outside of the GL. Scale bars, $100 \mu \mathrm{m}$.

contrast to P14 controls, Frizzled9-CreER ${ }^{\mathrm{TM}}$; Foxg1-ablated mice consistently lacked a compact SGZ made up of GFAP ${ }^{+}$ cells. Instead, GFAP ${ }^{+}$cells were disarrayed, especially those in the infrapyramidal blade.

(Figure legend continued.) locus represent probes used for Southern analysis. Red triangles represent loxP sites (Cre recombinase substrate). A, Apoll site; B, BamHI site. P1 and P2 represent the genotyping primers. $\boldsymbol{b}$, Cre (green) and GFAP (red) double immunostaining of the Frizzled9-CreER ${ }^{\mathrm{TM}}$ brain at postnatal day 5. Cre was expressed in GFAP ${ }^{+}$neural stem cells. c, Cre (green) activity was also detected in calretinin ${ }^{+}$(red) and $\mathrm{NeuN}^{+}$(red) postmitotic neurons. d, X-gal staining of Frizzled9-CreER ${ }^{\mathrm{TM}}$; Rosa26-lacZ mice at P14 after P5 TM induction. The strongest recombination activity was limited to the DG. $\boldsymbol{e}$, Foxg1 was detected in Frizzled9CreER $^{{ }^{T M}}$ and Frizzled9-CreER ${ }^{{ }^{T M}}$; Foxg1-ablated brains at P14. A $>90 \%$ loss of FoxG1 was observed in mutant DGs. $f$, NeuN staining of P14 brains revealed a decreased number of NeuN ${ }^{+}$ granule cells in mutant DGs. Severe abnormalities were observed in the DG. $\boldsymbol{g}$, Morphological changes in the Foxg1-ablated DG. From rostral (top) to caudal (bottom), DGs showed a severe reduction in size and a nearly complete loss of the infrapyramidal blade. $\boldsymbol{h}$, Quantification of morphological changes in mutant DGs $[n=4, \mathrm{WT} ; n=4$, mutant (MU)]. The area of the DG (left) and the length of both the suprapyramidal blade (middle) and the infrapyramidal blade (right) decreased in different levels in mutant DGs. Histograms represent mean $\pm S D,{ }^{*} p<$ $0.05,{ }^{* * *} p<0.0005,{ }^{* * * *} p<0.00005$, Student's $t$ test. Scale bars, $100 \mu \mathrm{m}$.
In addition, we observed migration defects in granule cells following postnatal Foxg1 inactivation. Sections were stained with proxl and calretinin, markers for granule cells and immature neurons, respectively. In P6 control DGs, prox ${ }^{+}$granule cells were densely packed to form the suprapyramidal and infrapyramidal blades (Fig. 2c). In mutant DGs, by contrast, the boundary between the two blades was no longer marked or clear, with cells evenly distributed ectopically in the GL and hilus. At P14 in control DGs, calretinin ${ }^{+}$immature neurons were located at the inner sides of the suprapyramidal and infrapyramidal blades (Fig. $2 f$ ). In mutant DGs, however, these cells failed to migrate properly. Calretinin ${ }^{+}$cells were occasionally ectopically located inside and outside of the GL (Fig. $2 f$, arrowheads). Together, these data suggest that Foxg1 activity is required for proper formation of the SGZ and for the distribution of dentate progenitors and granule cells.

Loss of Foxg1 results in malformation of the secondary radial glial scaffold in the dentate gyrus

The GL develops in a radial, outside-in gradient pattern (Thorgeirsson et al., 1979; Eckenhoff and Rakic, 1984; Crespel et al., 2002), with the position of newborn neurons near their site of 
origin. This process requires a glia-guided migration step, as in the cerebellum or DG (Gregg and Weiss, 2003; Weiss et al., 2003), suggesting a possible correlation between the migration defect of progenitor and granule cells and the disorganization of GFAP ${ }^{+}$ glia in mutant DGs. Indeed, the secondary radial glial scaffold initially develops in the first postnatal week and contributes to the postnatal generation of granule neurons as the primary NSCs in the SGZ (Altman, 1962; Altman and Das, 1965; Reznikov, 1991; Kempermann et al., 1997a,b). Possibly, therefore, the deletion of Foxg1 at P5 disturbed the development of the secondary radial glial scaffold. To examine the spatiotemporal distribution of radial glial cells in the postnatal mutant DG, we used molecular markers that label radial glial cells (Kornack and Rakic, 2001; Bonfanti and Peretto, 2007; Pinto and Götz, 2007). BLBP immunoreactivity is largely confined to the soma and nuclei of secondary radial cells within the SGZ. The unbranched radial processes extending toward ML can be visualized by GFAP immunoreactivity. At P14, in contrast to controls, $\mathrm{BLBP}^{+}$cells in Frizzled9CreER $^{\mathrm{TM}}$; Foxg1-ablated mice were scattered across the DG and observed ectopically in the GL (see Fig. 6a). In P7 mutant DGs, $\mathrm{GFAP}^{+}$fibers were still present (Fig. $3 a, a^{\prime}$ ). However, unlike the well separated radial fibers in controls, these fibers were highly intercrossed. Notably, the $\mathrm{GFAP}^{+}$scaffold extending to the hilus was absent in mutant DGs (Fig. $3 b, b^{\prime}$ ). Because this scaffold may guide progenitors in the dentate migration stream to the hilus (Förster et al., 2002; Frotscher et al., 2003; Weiss et al., 2003; Zheng and Feng, 2006), the absence of these fibers in mutants may explain the accumulation of $\mathrm{BrdU}^{+}$cells we observed in the migration route (Fig. 2d). At P14, most GFAP ${ }^{+}$long fibers had disappeared from the infrapyramidal blade of the mutant DGs (Fig. $3 f, f^{\prime}$ ). Those fibers that remained in the suprapyramidal blade often exhibited a translocated soma from the SGZ into the $\mathrm{GL}$, with their processes ramified within the GL (Fig. $\left.3 g, g^{\prime}\right)$. This cellular morphology may indicate astroglial differentiation (Chiang et al., 1996; McManus et al., 1999; Weiss et al., 2003; Dasgupta and Gutmann, 2005; Brunne et al., 2010). In the infrapyramidal blade, most $\mathrm{GFAP}^{+}$or $\mathrm{BLBP}^{+}$cells displayed excessive arborization, suggestive of a transition to an astrocytic fate. These data indicate that Foxg1 activity contributes to the formation of the secondary radial glial scaffold. It is worth noting that we did not detect obvious defects in the remnant primary radial glial scaffold at P7 (Fig. 3d, $d^{\prime}$ ). The essentially intact primary radial glial scaffold may partially explain the remaining $\mathrm{Tbr}^{+}$cell band in mutant DGs (Fig. $2 d$ ). These cells may have migrated along the primary radial glial scaffold to the MZ at relatively early stages.

In addition, an abnormal increase of $\mathrm{GFAP}^{+}$cells was detected both at P7 and P14. This increase was most pronounced in the infrapyramidal blade (Fig. $3 c, c^{\prime}$ ). Since GFAP can label both radial glial cells and astrocytes, we used an additional marker, the intermediate filament protein vimentin, to identify these $\mathrm{GFAP}^{+}$ cells. Vimentin is a marker transiently expressed during radial glial cell development. In the second postnatal week, few astrocytes of the ML express vimentin (Brunne et al., 2010). By coimmunostaining of GFAP and vimentin, we found in P14 mutant DGs that a large portion of those abnormally increased $\mathrm{GFAP}^{+}$cells were colabeled by the two markers (Fig. $\left.3 h, h^{\prime}, i, i^{\prime}\right)$, suggesting they were ectopic radial glial cells. These cells, their organization severely disrupted from Foxg1 deprivation, might normally be the radial glial scaffold for forming the infrapyramidal blade.

\section{Dynamic changes of dentate gyrus cell compartments following Foxg1 deletion}

Postnatal dentate hippocampal neurogenesis is a constitutive but highly regulated process. Progenitors in the SGZ produce glutamatergic neurons that populate the DG GL (Steiner et al., 2004). Primary progenitor cells, also called type-1 cells or NSCs, exhibit morphology typical of radial glia and divide slowly to produce astroglia progenitor cells and IPCs. At the end of the transient amplifying progenitor phase, progenitors exit the cell cycle and gradually mature to become astrocytes or neurons. The remarkably reduced size of mutant DGs was inevitably accompanied by a dynamic change in DG cell compartments. To determine precisely which cell type was affected following P5 Foxg1 ablation, we categorized DG cells into four compartments based on statespecific markers. We used GFAP to label NSCs and astrocytes, Tbr2 to label IPCs, and calretinin and NeuN to label immature and mature neurons, respectively (markers were chosen based on references cited in Materials and Methods). The absolute numbers and relative percentages of these compartments based on total DG cell number (labeled by DAPI) were evaluated at P7 or P14 (Fig. 4). Our results demonstrate a reduced number of NSCs and IPCs and a relative increase in astrocytes. The absolute number of postmitotic neurons decreased after a transient rise.

Following Foxg1 ablation, the size of the DG was reduced, accompanied by a decrease in the total number of DG cells (Fig. $4 a$ ) (no significant difference at P7, $p=0.2261$ ). This decrease was more pronounced at P14 $\left(p<2.8 \times 10^{-5}\right)$. In control DGs, the absolute number of NSC compartments remained relatively stable from P7 to P14 (Fig. 4b). The relative percentage of these cells, however, fell rapidly from $23.1 \%$ at P7 to $3.2 \%$ at P14 (Fig. $4 b$ ). This decrease in the relative percentage of NSCs is likely due to rapid and dramatic postnatal expansion in the total number of DG cells. In contrast to control, Foxg1 inactivation led to a significant decrease in the absolute number of DG NSCs at P7 (Fig. 4b; $p=0.0011$ ), and this number remained low until P14 (Fig. 4b; $\left.p<1.7 \times 10^{-6}\right)$. Accordingly, the relative number of NSCs was lower in mutant DGs relative to control at both P7 and P14 (Fig. $4 b^{\prime} ; p<0.007$ and $p<2.9 \times 10^{-4}$, respectively). The relative number of Tbr2 ${ }^{+}$cells (corresponding to IPCs) underwent a decrease from 23.7 to $5.8 \%$ in control DGs (Fig. $4 c^{\prime}$ ). In mutant DGs, this percentage decreased significantly from 18 to $2.5 \%$ (Fig. $4 c^{\prime} ; p<0.02$ and $p<4.8 \times 10^{-7}$, respectively). However, the absolute number of Tbr2 ${ }^{+}$cells did not decrease immediately in mutant DGs at P7 (Fig. 4c; $p=0.1244$ ) but did fall significantly by P14 (Fig. $4 c ; p<6 \times 10^{-10}$ ). Calretinin ${ }^{+}$cells located in the GL mark immature neurons. Along with $\mathrm{NeuN}^{+}$mature neurons, both populations were considered postmitotic neurons. Interestingly, the absolute cell number in this compartment was transiently elevated in P7 mutants (Fig. $4 d ; p=0.0014$ ) but then decreased dramatically at P14 (Fig. $4 d ; p<0.02$ ). The relative number of calretinin ${ }^{+}$and $\mathrm{NeuN}^{+}$cells also transiently rose in P7 mutants (Fig. $4 d^{\prime} ; p=0.0261$ ) but showed no difference at P14 (Fig. $4 d^{\prime} ; p=0.3576$ ). As mentioned, we observed a possible increase in the number of astrocytes in mutant DGs. To confirm this observation, we used GFAP expression and the multiprocess morphological features of astrocytes to identify these cells. At P7 and P14, the total number of astrocytes in mutant DGs was comparable to that of controls (Fig. $4 e ; p=0.0784$ and $p=0.787$, respectively), but the relative number of astrocytes rose remarkably at both stages (Fig. $4 e^{\prime} ; p<9.1 \times 10^{-5}$ and $p<1.1 \times 10^{-8}$, respectively). 

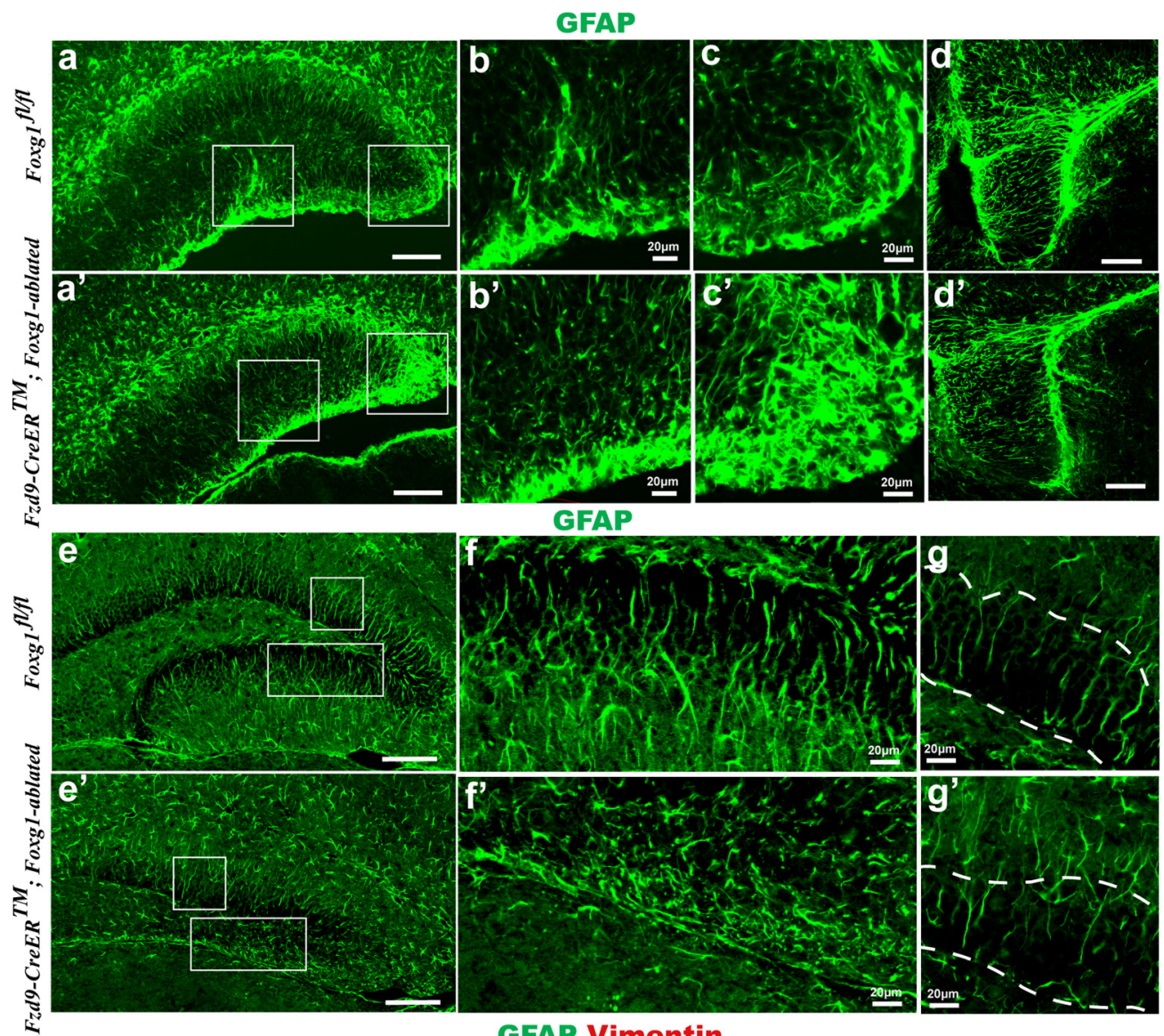

GFAP Vimentin

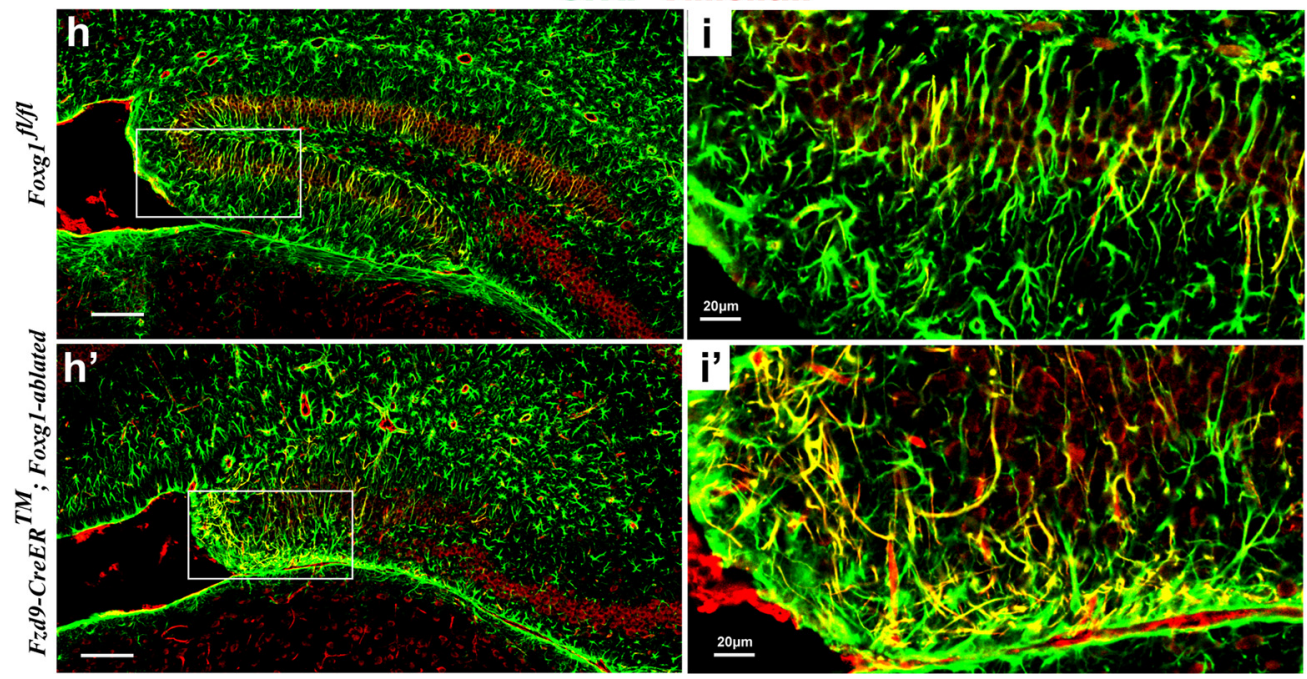

Figure 3. Malformation of the secondary radial glial scaffold in the dentate gyrus of Frizzledg-CreER ${ }^{\mathrm{TM}} ;$ Foxg1-ablated mutants. Controls and Frizzled9-CreER ${ }^{\mathrm{TM}}$; Foxg ${ }^{\mathrm{f} / \mathrm{fl}}$ mice received TM treatment at P5. $\boldsymbol{a}-\boldsymbol{d}^{\prime}$, GFAP immunostaining of controls and the Frizzled9-CreER ${ }^{\mathrm{TM}}$ brain at postnatal day $7 . \boldsymbol{a}^{\prime}$, In P7 mutant DGs, GFAP ${ }^{+}$fibers were still present but were highly intercrossed. $\boldsymbol{b}^{\prime}$, The GFAP ${ }^{+}$scaffold extending to the hilus was absent in mutant DGs. $\boldsymbol{c}^{\prime}$, Increased GFAP ${ }^{+}$cells were detected in mutant DGs. $\boldsymbol{d}^{\prime}$, No obvious defect was observed in the primary radial glial scaffold at P7. $\boldsymbol{e}-\boldsymbol{g}^{\prime}$, GFAP immunostaining of controls and the Frizzled9-CreER ${ }^{\text {TM }}$ brain at postnatal day $14 . \boldsymbol{f}^{\prime}$, In mutant DGs, most GFAP ${ }^{+}$Iong fibers had disappeared from the infrapyramidal blade. $\boldsymbol{g}^{\prime}$, Fibers that remained in the suprapyramidal blade exhibited a translocated soma from the SGZ into the GL, with their processes ramified within the GL. Dashed lines outline the boundary of GL. $\boldsymbol{h}-\boldsymbol{i}^{\prime}$, Double immunofluorescent staining of GFAP (green) and vimentin (red) in P14 control and mutant DGs. An abnormal increase in GFAP ${ }^{+}$cells was detected in mutant DGs. This increase was most pronounced in the infrapyramidal blade. $\boldsymbol{i}^{\prime}$, Among this abnormal number of GFAP ${ }^{+}$cells, many were colabeled by GFAP and vimentin, suggesting they were ectopic radial glial cells. Scale bars, $100 \mu \mathrm{m}$.

Reduced proliferation of NSCs and IPCs in Foxg1-ablated dentate gyrus

The altered size of DG cellular compartment populations can result from distinct kinetic mechanisms, including altered NSC proliferation rates, altered cell death rates, and/or an altered frequency of transition from NSCs to downstream compartments. Among the altered cellular compartments in mutant DGs, those in NSCs and IPCs demonstrated the most immediate and pronounced reduction. We inferred that this change was due to an inability to proliferate. The proliferation rates of NSCs and IPCs were therefore measured.

We found that the postnatal inactivation of Foxg1 resulted in a severe impairment of progenitor proliferation. BrdU pulse injec- 


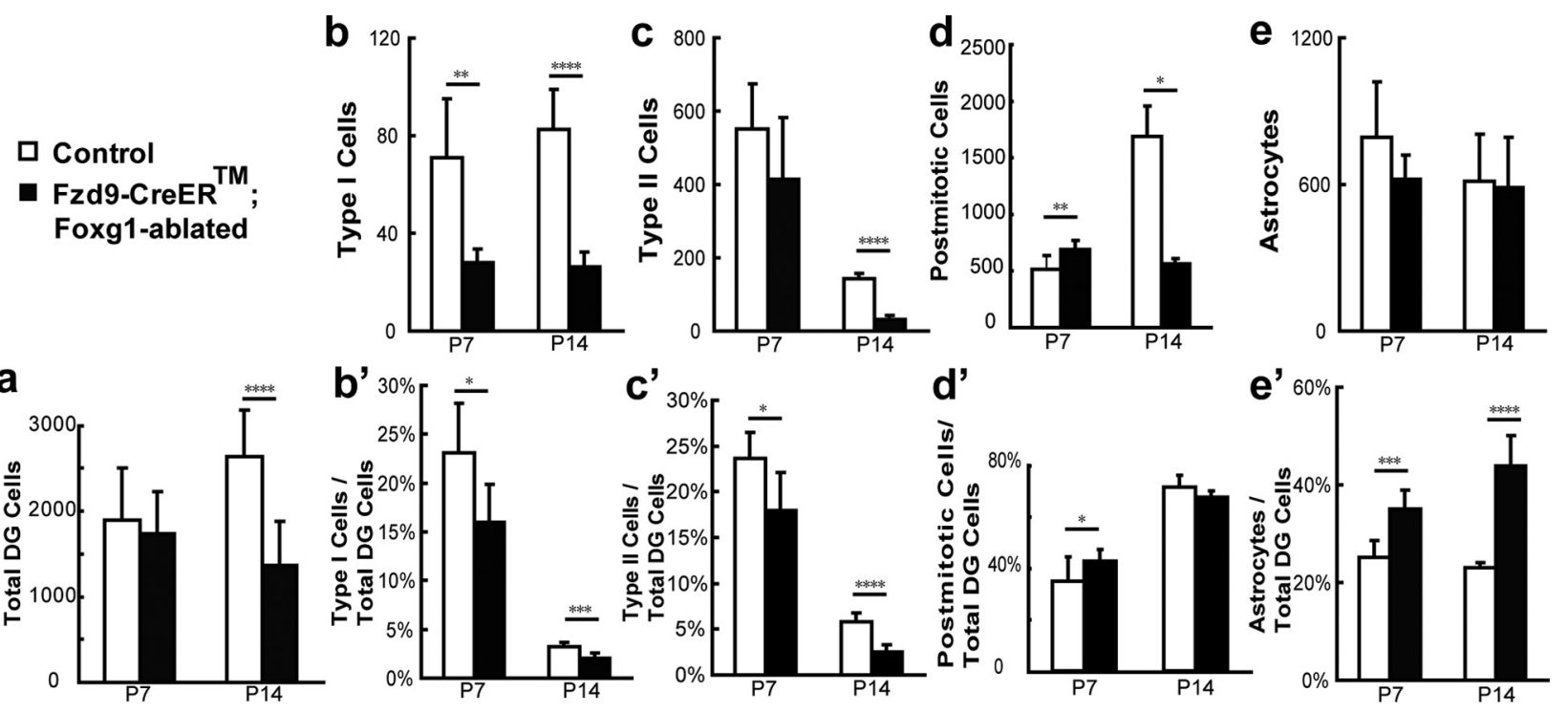

Figure 4. Dynamic changes of dentate gyrus cell compartments following Foxg 1 deletion. Controls and Frizzledg-CreER ${ }^{\mathrm{TM}}$; Foxg ${ }^{\text {fl/fl }}$ mice received TM treatment at P5. $\boldsymbol{a}$, The absolute numbers of the total number of DG cells, showing a significant reduction in mutant DGs at P14 $(n=3, \mathrm{WT} ; n=4, \mathrm{MU}) . \boldsymbol{b}, \boldsymbol{b}^{\prime}$, The absolute numbers and relative percentages of NSCs based on total DG cell number. $\boldsymbol{b}$, At both P7 $(n=3 ; 3)$ and P14 $(n=3 ; 4)$, the absolute number of NSCs fell in mutant DGs. $\boldsymbol{b}^{\prime}$, The relative percentage of NSCs also fell markedly in mutant DGs. $\boldsymbol{c}, \boldsymbol{c}^{\prime}$, The absolute numbers and relative percentages of IPCs based on total DG cell number. $c$, At P14 $(n=4 ; 3)$, the absolute number of IPCs fell in mutant DGs. $c^{\prime}$, At both P7 and P14 $(n=3 ; 3)$, the relative percentage of IPCs fell markedly in mutant DGs. $\boldsymbol{d}, \boldsymbol{d}^{\prime}$, The absolute numbers and relative percentages of postmitotic neurons based on total DG cell number. $\boldsymbol{d}$, The absolute number of postmitotic neurons was transiently elevated in P7 mutants $(n=5 ; 3)$, but then decreased dramatically at P14 $(n=3 ; 3)$. $\boldsymbol{d}^{\prime}$, The relative percentage of postmitotic neurons was elevated in P7 mutants $(n=5 ; 3)$. $\boldsymbol{e}, \boldsymbol{e}^{\prime}$, The absolute numbers and relative percentages of astrocytes based on total DG cell number. $\boldsymbol{e}$, At P7 $(n=3 ; 3)$ and P14 $(n=3 ; 4)$, the total number of astrocytes in mutant DGs was comparable to that of controls. $\boldsymbol{e}^{\prime}$, The relative number of astrocytes of astrocytes rose remarkably at both stages in mutant DGs. Histograms represent mean $\pm S D$. ${ }^{*} p<0.05,{ }^{* *} p<0.005$, ${ }^{* * *} p<0.0005$, $* * * 0<0.00005$, Student's $t$ test.

tions were performed at P7 ( $2 \mathrm{~d}$ after TM administration), and mice were killed after $4 \mathrm{~h}$. The number of $\mathrm{BrdU}^{+}$cells in the DG underwent a 2.6 -fold reduction (Fig. $5 b ; p<2 \times 10^{-5}$ ). As a separate marker for proliferation, Ki67 staining was performed on P7 and P14 sections. At both stages, $\mathrm{Ki}^{+}{ }^{+}$cells in the DG were reduced nearly threefold (2.8-fold at both stages) (Fig. $5 a$; $p<1.2 \times 10^{-6}$ and $p<2.1 \times 10^{-9}$, respectively). This marked reduction in proliferating cells was far more severe than expected. In previous studies of Foxg1 ${ }^{+/-}$DGs, the acute BrdU-labeling index was not markedly altered, and significant decreases were observed only at P100 (Shen et al., 2006). Considering the possible causes for this phenomenon, we noted that prolonging the neural progenitor cell cycle would decrease the number of cells exiting the cell cycle in a given time interval, thus leading to fewer $\mathrm{BrdU}^{+}$or $\mathrm{Ki}^{+}{ }^{+}$cells. To preclude the possibility of interference from changes in cell cycle length, we performed BrdU/Ki67 double labeling. P5 mice received a TM injection followed by BrdU administration after $6 \mathrm{~h}$. Brains were harvested $18 \mathrm{~h}$ later. The ratio of BrdU and Ki67 double-labeled cells divided by the number of $\mathrm{BrdU}^{+}$cells represents the proportion of cells that completed one cell cycle and re-entered another. We did not find a significant difference between control and mutant mice (Fig. $5 c$; $p=0.62)$ in this measurement, precluding the involvement of cell cycle length in the reduction of the number of proliferating cells.

The reduced number of dividing cells implied a diminished proliferative ability of DG NSCs and progenitors. A number of loss-of-function studies of embryonic (Xuan et al., 1995; Hanashima et al., 2002) or postnatal brains (Shen et al., 2006) suggest that Foxg1 promotes precursor self-renewal and inhibits cell cycle exit. To test for these possibilities, we calculated the proliferation rates of NSCs and IPCs. NSCs can be identified by positive staining for GFAP and radial glia morphology. In control
DGs, NSCs were distributed regularly in the SGZ. Their cell bodies were located in the lowest part of the GL, and they extended long processes that traversed the GL. Within the GL, these long processes rarely branched. A few of these cells were colabeled with Ki67 (Fig. 5d; 8\% for P7 and 5\% for P14). In mutant DGs, most of these $\mathrm{GFAP}^{+}$radial glial cells showed dislocated cell bodies into the GL and did not form a morphologically normal SGZ. Meanwhile, the processes of these cells branched frequently in the GL. Moreover, a smaller portion of this cell population, compared to controls, coexpressed Ki67 (4\% for P7 and 1.5\% for P14; $p<$ $0.002, p<0.007$, respectively). Tbr $2^{+}$IPCs in control DGs, although actively proliferating (Fig. $5 e$; 30 and $40 \%$ coexpress Ki67 at P7 and P14, respectively), were restricted to a band in the SGZ. In contrast, Tbr $2^{+}$IPCs in mutant DGs exhibited an irregular distribution and less colabeling with Ki67 (16.8\% for P7 and 26\% for P14; $p<1.9 \times 10^{-7}$ and $p<0.004$, respectively). These results suggest a reduced proliferation rate of both NSCs and IPCs in Foxg1-ablated DGs.

\section{Foxg1 inhibits both gliogenesis and neurogenesis}

The altered size of DG cellular compartments may also result from alterations in the transition from progenitors to their terminal-differentiated progeny. Previous views emphasize an antigliogenic function of Foxg1. This function was first described in Drosophila, in which two Foxg1 orthologs, Sloppy paired-1 (Slp1) and Sloppy paired-2 (Slp2), were believed to promote neurogenesis at the expense of gliogenesis (Mondal et al., 2007). More recently, experiments conducted on cultured cortical neural precursors led to the conclusion that Foxg1 inhibits gliogenesis and promotes neurogenesis (Brancaccio et al., 2010). To verify these findings in vivo, we examined the astroglial and neuronal output of the DG. Surprisingly, we found that deletion of Foxg1 promoted both gliogenesis and neurogenesis (Fig. 6). Based on 

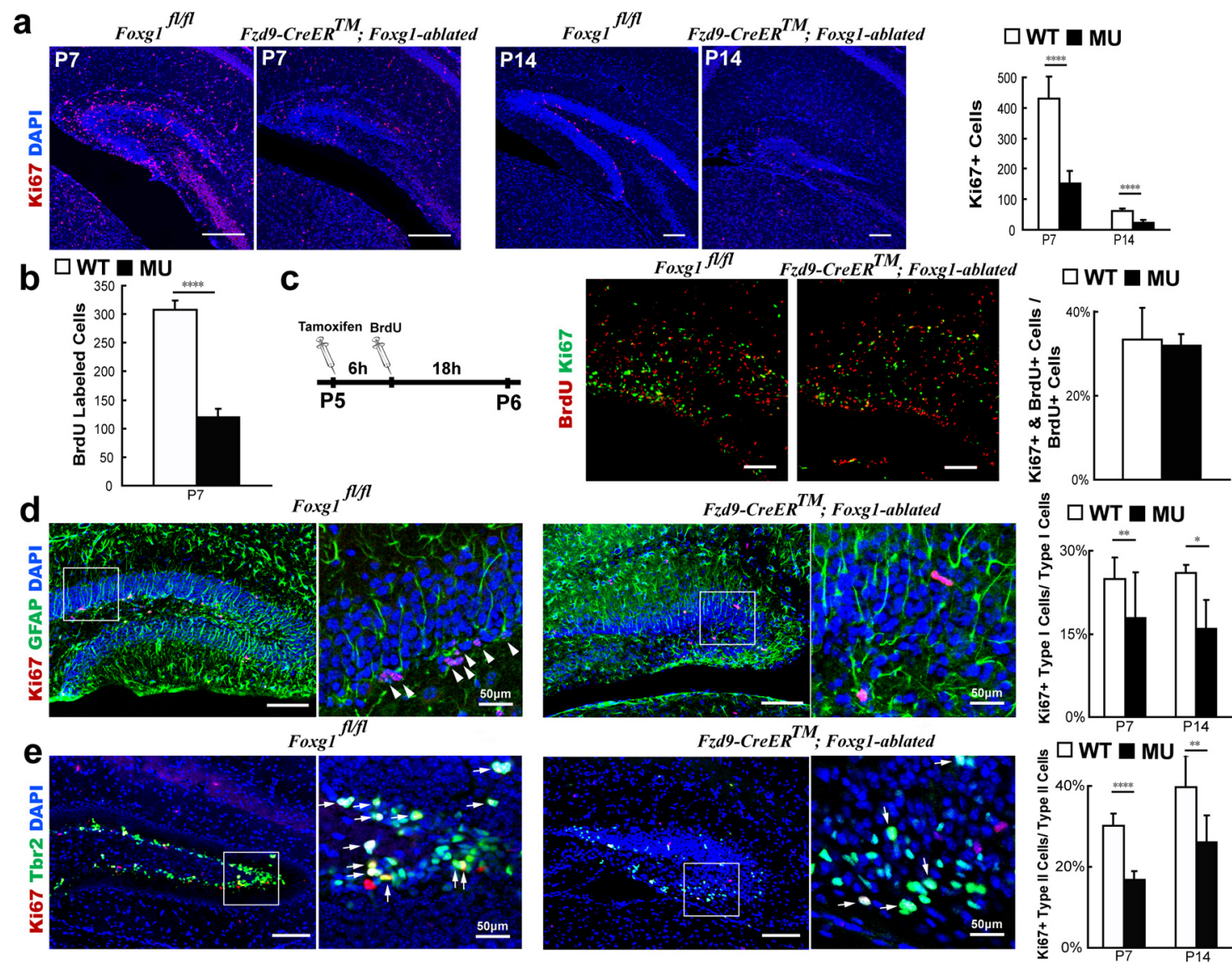

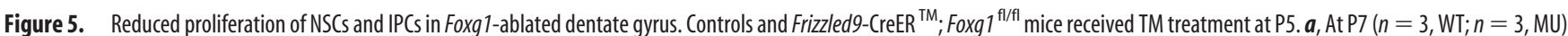
and P14 $(n=3 ; 4), \mathrm{Ki} 7^{+}$cells in the mutant DGs were reduced nearly threefold (2.8-fold at both stages). $\boldsymbol{b}$, At P7, the number of BrdU ${ }^{+}$cells in the mutant DGs underwent a 2.6-fold reduction $(n=3$; 4). c, Left, Schematic of TM and BrdU injections. Right, The ratio of BrdU (red) and Ki67 (green) double-labeled cells divided by the number of BrdU-labeled cells did not differ between control and mutant mice $(n=3 ; 3)$. d, The portion of NSCs that coexpressed Ki67 (red) was reduced in mutant DGs at both P7 $(n=3 ; 3)$ and P14 $(n=3 ; 4)$. e, The portion of IPCs that coexpressed Ki67 (red) was also reduced in mutant DGs at both P7 $(n=3 ; 3)$ and P14 $(n=3 ; 3)$. Histograms represent mean \pm SD. ${ }^{*} p<0.05,{ }^{* *} p<0.005,{ }^{* * * *} p<0.00005$, Student's $t$ test. Scale bars, $100 \mu \mathrm{m}$.

these results, we assume that Foxg1 might maintain a balance between progenitor self-renewal and differentiation. Without Foxg1, this balance shifted DG progenitor cells toward neuronal and astrocytic differentiation, quickly depleting the progenitor population and resulting in a smaller final progenitor pool of neurons and astrocytes.

\section{Lack of Foxg1 promotes gliogenesis}

Following Foxg1 ablation at P5, we observed an increase in astrocyte numbers at different stages (Fig. $4 e, e^{\prime}$ ). A possible transition from NSCs to astrocytes was also observed (Fig. $3 g$ ). In normal DGs, BLBP labeled the cell bodies of NSCs and astrocytes. In P14 mutant DGs, BLBP staining revealed a depletion of NSCs, which was consistent with GFAP staining (Fig. $6 a$ ). In addition, more astrocytes were observed in the ML and the stratum lacunosummoleculare. At P7, $\mathrm{Ki}_{67}{ }^{+}$proliferating cells were divided into three groups according to their colabeling with distinct markers. $\mathrm{Ki}^{+} 7^{+} / \mathrm{GFAP}^{+}$astrocytes represented proliferating astrocyte progenitors, $\mathrm{Ki}^{+} 7^{+} / \mathrm{GFAP}^{+}$NSCs represented proliferating NSCs, and $\mathrm{Ki} 67^{+} / \mathrm{Tbr} 2^{+}$cells represented proliferating IPCs. While the $\mathrm{Ki}^{+} 7^{+} \mathrm{GFAP}^{+}$NSC compartment remained unchanged (Fig. $6 b ; p=0.1706$ ), we observed a twofold (1.97) increase in the $\mathrm{Ki} 67^{+} / \mathrm{GFAP}^{+}$astrocyte compartment in mutant mice $(p=0.0052)$, accompanied by a slight reduction in the population of the $\mathrm{Ki}^{+} 7^{+} / \mathrm{Tbr} 2^{+}$compartment $(p=0.0051)$. This result suggests an increased ratio of proliferating astrocytic progenitors. To obtain more direct evidence of increased gliogenic output, BrdU birthdating was performed. BrdU was administered at P6, 24 h following Foxg1 inactivation. Brains were harvested at P14, and BrdU/GFAP double labeling was conducted (Fig. $6 c$ ). We consistently observed an increased ratio of $\mathrm{BrdU}^{+}$astrocytes among the total number of $\mathrm{BrdU}^{+}$cells (Fig. $6 d$; from 20.8 to $34.6 \%, p<5.6 \times$ $\left.10^{-4}\right)$. Together, these data suggest increased gliogenesis in the DG following Foxg1 inactivation.

An additional notable finding in the mutant DG was a small portion of $\mathrm{GFAP}^{+}$cells exhibiting an astrocytic shape (i.e., with multiple and irregular processes) colabeled with the neuronal markers prox1 (Fig. $6 g$ ) or Tbr2 (Fig. 6h). These cells were primarily located within the outer DG (i.e., the marginal zone of the ML or the outer GL). Such colabeling was not observed in wildtype DGs. Tbr2 is a TF initially expressed in amplifying neuronal progenitors (late type-2a cells) and is maintained in type-2b cells. $\mathrm{Tbr}^{+}$progenitors generate only granule cells, not astrocytes (Kimura et al., 1999; Englund et al., 2005; Hodge et al., 2008). Thus, it would be abnormal to observe its colocalization with GFAP in NSCs or astrocytes. Similarly, prox1 is a marker that initially appears in type-3 cells and is primarily expressed in postmitotic neurons, which precludes its coexpression with GFAP. The abnormal expression of these neuronal markers in $\mathrm{GFAP}^{+}$ astrocyte-like cells indicated a possible fate determination transition between neurons and astrocytes. However, because 

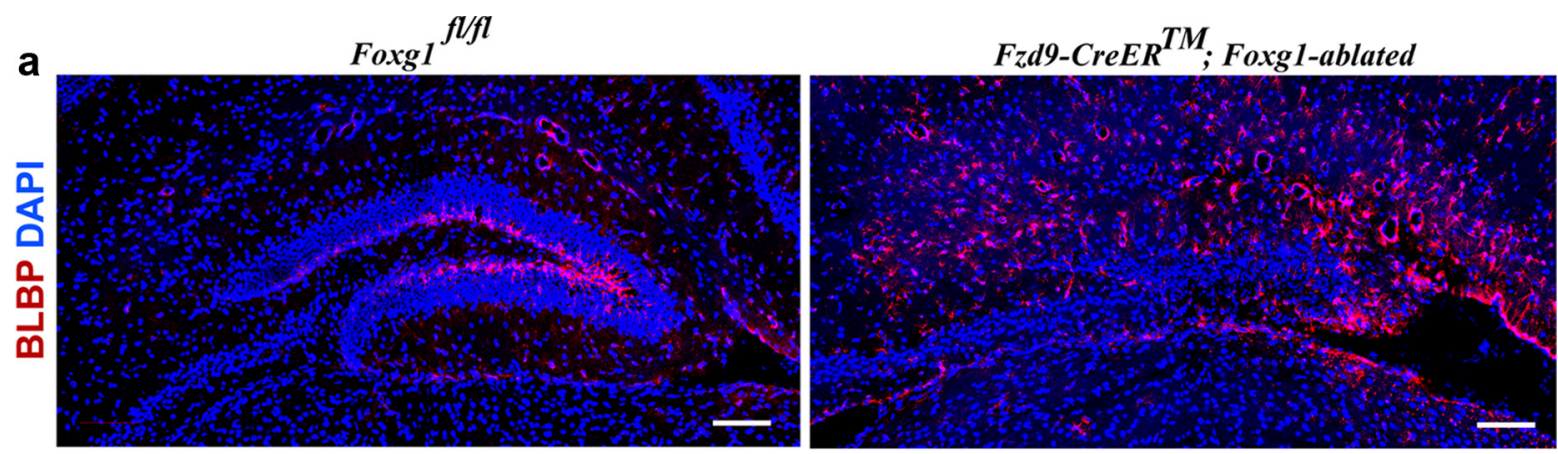
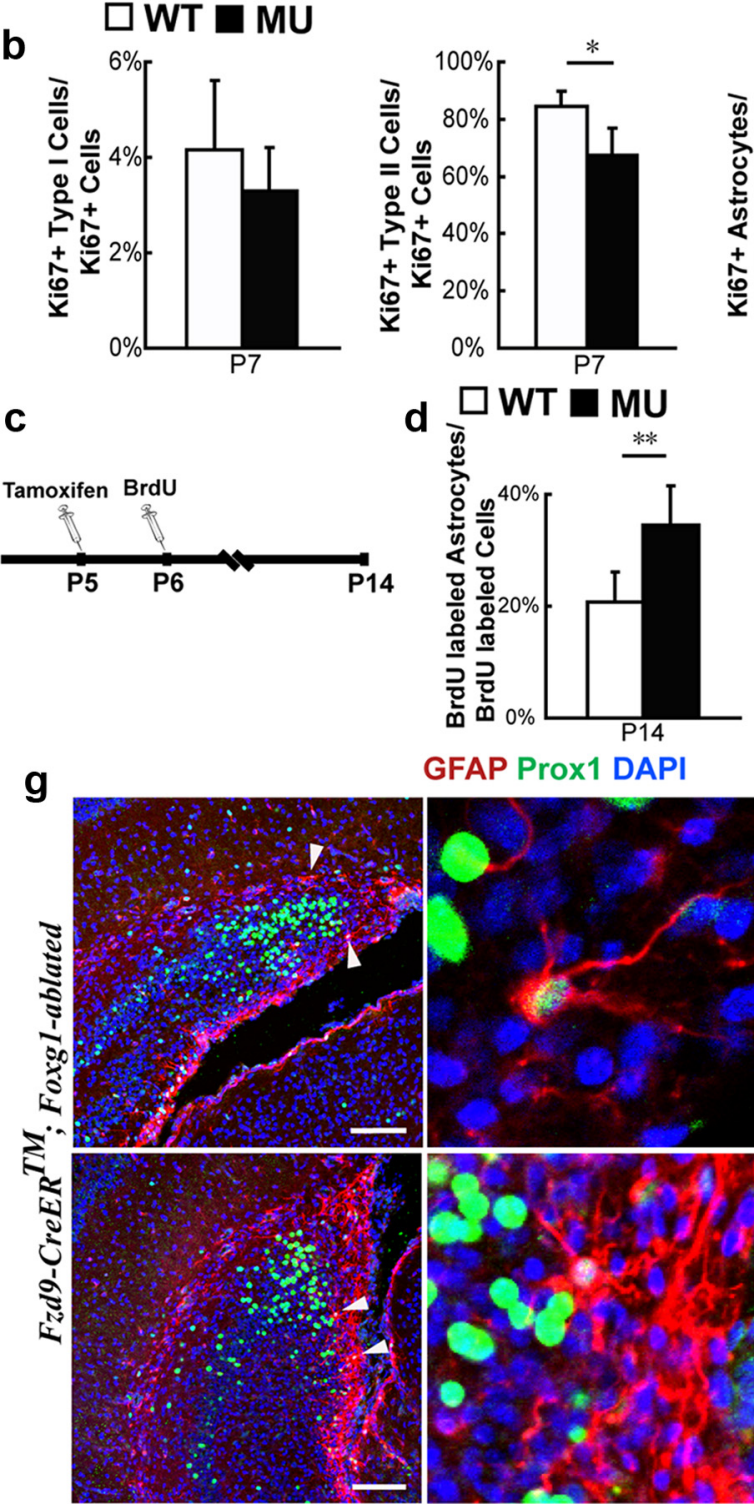
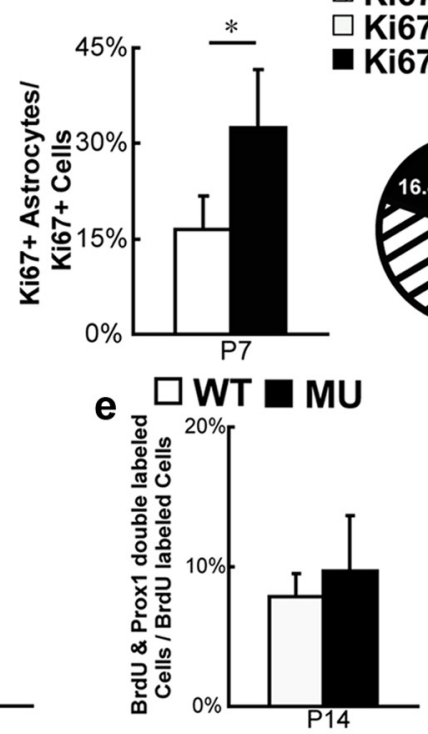

GFAP Prox1 DAPI
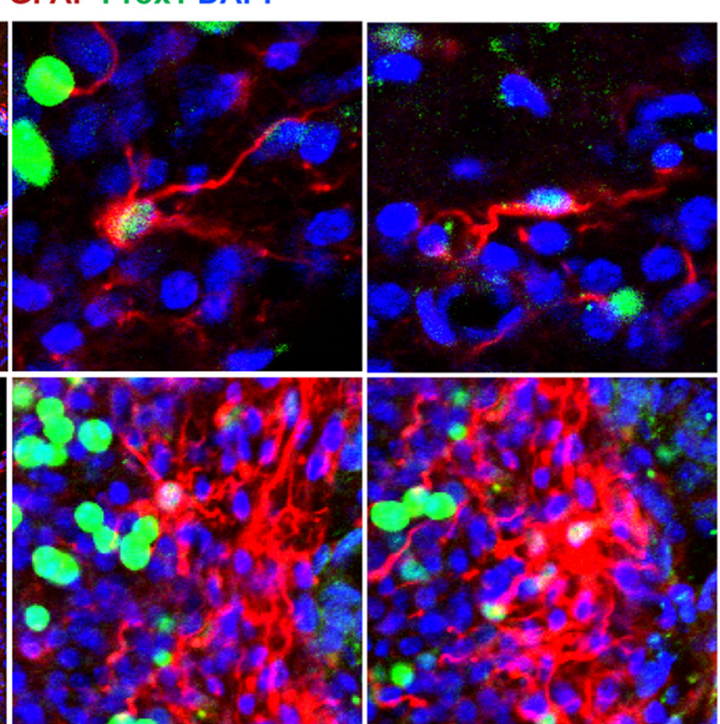

\section{Ki67+ Type II Cells \\ Ki67+ Type I Cells \\ Ki67+ Astrocytes}

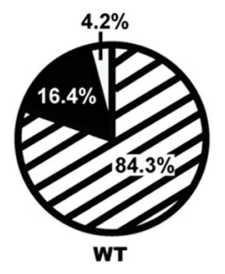

f

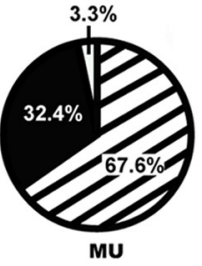

$\square$ WT $\square \mathrm{MU}$

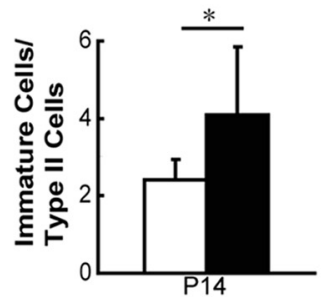

GFAP Tbr2 DAPI

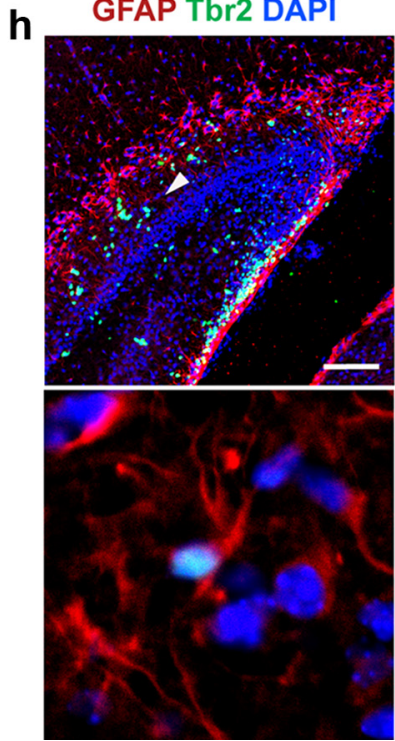

Figure 6. Foxg 1 inhibits both gliogenesis and neurogenesis. Controls and Frizzledg-CreER ${ }^{\mathrm{TM}} ;$ Foxg ${ }^{\text {fl/fl }}$ mice received TM treatment at P5. $\boldsymbol{a}$, BLBP staining at P14 revealed a depletion of NSCs and an increase of astrocytes in the ML and the stratum lacunosum-moleculare in mutant DGs. $\boldsymbol{b}$, The proportion of Ki67 ${ }^{+} / \mathrm{GFAP}^{+}, \mathrm{Ki} 7^{+} / \mathrm{Tbr}^{+}{ }^{+}$, and Ki67 ${ }^{+} / \mathrm{GFAP}^{+}$astrocyte compartments in Ki67-labeled proliferating cells $\left[n=3, \mathrm{WT} ; n=3\right.$, mutant (MU)]. In mutant DGs, the Ki67 ${ }^{+} / \mathrm{GFAP}^{+} \mathrm{NSC}$ compartments remained unchanged, with an enlarged $\mathrm{Ki}_{6}{ }^{+} / \mathrm{GFAP}^{+}$astrocyte compartment and a reduced Ki67 ${ }^{+} / \mathrm{Tbr2}{ }^{+}$compartment compared with controls. c $\boldsymbol{e}$, BrdU birthdating. $n=3 ; 3$. c, Schematic of TM and BrdU injections.d, The ratio of $\mathrm{BrdU}{ }^{+}$astrocytes among the total number of $\mathrm{BrdU}{ }^{+}$cells increased in mutant DGs. $\boldsymbol{e}$, The ratio of $\mathrm{BrdU}{ }^{+} /$prox $^{+}$neurons among the total number of BrdU ${ }^{+}$cells slightly increased in mutant DGs, with no statistical significance. $f$, The index of calretinin ${ }^{+}$immature cells/Tbr2 ${ }^{+} \mathrm{IPCs}$ at P14 was elevated in mutant DGs, indicating accelerated differentiation from IPCs to neurons. $\boldsymbol{g}, \boldsymbol{h}$, A small portion of GFAP ${ }^{+}$cells (red) exhibiting an astrocytic shape (i.e., with multiple and irregular processes) colabeled with the neuronal markers prox 1 (green) or Tbr2 (green). These cells were primarily located within the outer DG (i.e., the marginal zone of the ML or the outer GL). Histograms represent mean \pm SD. ${ }^{*} p<0.05,{ }^{* *} p<$ 0.005. Scale bars, $100 \mu \mathrm{m}$, Student's $t$ test. 
abnormal colabeling provides only morphological evidence, we cannot say whether Foxg1 drove this "transition" in neurons or astrocytes. Further fate-mapping and functional studies of these abnormal cells need to be conducted.

\section{Lack of Foxg1 promotes neurogenesis}

As mentioned above, we detected an increase in postmitotic neurons in P7 mutants (Fig. 4d). This increase included an expansion of their absolute number and their relative frequency. The most likely explanation for this result is overdifferentiation of neural progenitors. Based on this hypothesis, we calculated the $\mathrm{Yi} / \mathrm{X}$ transition index of calretinin ${ }^{+}$immature cells/Tbr2 ${ }^{+}$IPCs at $\mathrm{P} 14$. This ratio reflects the rates at which element $\mathrm{X}$ transits to its adjacent downstream compartment Yi. We observed a twofold upregulation in mutant DGs (Fig. $6 f ; p=0.024$ ), indicating accelerated differentiation from IPCs to neurons. We then performed BrdU birthdating to obtain direct evidence of this acceleration. However, although BrdU birthdating revealed a slightly increased ratio of $\mathrm{BrdU}^{+} / \operatorname{prox}^{+}$neurons at P14 (Fig. $6 e)$, this increase was not statistically significant $(p=0.2471)$. Together with the substantially reduced neuronal lineage at P14, these findings led us to suspect a role for apoptosis. As expected, we observed massive apoptosis in the DG exclusively in the neuronal lineage. Astonishingly, apoptosis occurred as early as $0.5 \mathrm{~d}$ following Foxg1 deletion, and cell death persisted until at least P7 (Fig. 7). Under such conditions, we were still able to detect an increase in postmitotic neurons, further indicating upregulated neuronal differentiation. These findings raise the possibility that in previous Foxg1 knock-out models, excessive neuronal cell death may strongly mask the reinforced neurogenesis. Furthermore, in Foxg1 overexpression models, the stimulated survival of neurons may compensate for the antineurogenesis effect.

\section{Foxg1 may be required for the survival and maturation of postmitotic neurons}

Foxg1 is expressed in NSCs and IPCs in the SGZ, and previous findings have suggested that it is required for the maintenance of these progenitors. However, we detected stronger Foxg1 expression in postmitotic neurons (Fig. 7a). We observed a drastic decrease at P14 in the absolute number of postmitotic neurons in the absence of Foxg1 (Fig. 4d). To determine whether the reduced number of postmitotic neurons resulted solely from defective neurogenesis or was due to the effect of Foxg1 in stimulating postmitotic neuron survival, we analyzed cell death in the DG. In contrast to a previous study conducted in Foxg $1^{+/-}$mice, which reported unaltered cell death in the DG (Shen et al., 2006), we observed massive apoptosis following postnatal Foxg1 ablation.

Controls and Frizzled9-CreER ${ }^{\mathrm{TM}}$; Foxg1-ablated mice were killed at different time points following P5 TM treatment (Fig. $7 b, c)$. At $0.5 \mathrm{~d}$ after TM treatment, we observed dramatically increased cell death using cleaved caspase- 3 along the migratory streams from the dentate notch and in the DG (Fig. $7 b ; p=$ 0.0042 ). Fewer apoptotic cells were observed $2 \mathrm{~d}$ after TM treatment, but the difference between controls and mutants was still pronounced (Fig. $7 c ; p<1.7 \times 10^{-11}$ ). In controls, only a few cleaved caspase- $3^{+}$cells were detected in control DGs, while many caspase $-3^{+}$cells were colabeled with the postmitotic markers calretinin and NeuN in mutants (Fig. $7 d$ ). Colabeling of NSCs or astrocytes with cleaved caspase-3 was not observed (data not shown). These data demonstrate that most apoptotic cells had exited the cell cycle. However, we did not detect any cleaved caspase $-3^{+}$cells in control or mutant DGs at stages later than P7 (data not shown). This result suggests that cell death occurred rapidly following Foxg1 ablation, causing a sharp decrease in the neuronal population.

To eliminate any potential effects of defective neurogenesis, BrdU was intraperitoneally administrated $12 \mathrm{~h}$ following P5 TM treatment, and brains were harvested at P6 and P14 (Fig. 7e). Postmitotic neurons were divided into two groups according to BrdU incorporation. Newborn neurons were identified as BrdU and proxl double-positive cells, and postmitotic neurons were identified as $\mathrm{BrdU}^{-}$and prox ${ }^{+}$cells. We assessed the survival of existing postmitotic neurons in controls and mutants by counting only BrdU ${ }^{-} /$prox $^{+}$cells. Quantitative analysis at P6 demonstrated that Frizzled9-CreER ${ }^{\mathrm{TM}}$; Foxg1-ablated mice had $16.7 \%$ fewer $\mathrm{BrdU}^{-} /$proxl $^{+}$cells than control mice $(p<8 \times$ $\left.10^{-5}\right)$. At P14, this compartment had $60 \%$ fewer cells than that of control mice $\left(p<8 \times 10^{-5}\right)$. These results suggest that Foxg1 may be required for the survival of postmitotic neurons.

In addition, our results demonstrate that loss of Foxg1 may affect the normal maturation and function of postmitotic neurons. In control mice, calretinin labeled immature granule cells in the SGZ (Fig. $7 f$ ). Meanwhile, calretinin ${ }^{+}$axons of mossy cells traversed the GL and terminated on proximal granule cell dendrites, forming a functional band in the inner third of the ML. In mutant DGs, only traces of this band were evident (Fig. 7f), and the absolute number of mossy cells was decreased (data not shown). Detailed observations of granule cells in Frizzled9CreER $^{\mathrm{TM}}$; Foxg1-ablated mice revealed abnormal dendritic projections. Calretinin ${ }^{+}$immature granule cells were scattered and did not extend long, parallel dendrites, suggesting a maturation defect.

\section{Prenatal deletion of Foxg1 has little impact on the migration of primordial granule cells but severely disrupts the postnatal formation of secondary radial glial scaffold}

Foxg1 shows abundant expression in the hippocampus as early as E11.5 (Hébert and McConnell, 2000). During embryonic stage, the formation of primary radial glial scaffold is first apparent at around E14.5 (Li and Pleasure, 2005). After that, the earliest born granule neurons start their radial migration along the scaffold and form the primordial granular layer. Moreover, we demonstrate that postnatal deletion of Foxg1 causes more serious damage in the infrapyramidal blade of DG. However, the suprapyramidal blade of DG actually forms prenatally. Thus, to assess whether Foxg1 exerts a crucial role in these prenatal developmental events, Frizzled9-CreER ${ }^{\mathrm{TM}} ;$ Foxg $1^{\mathrm{fl} / \mathrm{fl}}$ mice were administered TM at E15.5. Because the suprapyramidal blade of DG does not become distinguishable until the postnatal stage, brains were examined at P5 and P14.

We first detected the expression pattern of Foxg1 in E15.5 embryonic hippocampus. At E15.5, Foxg1 was strongly expressed in the hippocampus ventricular zone (VZ) (Fig. 8a), but had a weaker immunoreactivity in the dentate area. Meanwhile, Foxg1 had massive colocalization with proliferating cells, especially in the $\mathrm{VZ}$ and dentate notch, which was shown by $1 \mathrm{~h}$ BrdU pulse injection (Fig. $8 a$, arrowheads). To examine the target cells and efficiency of our TM-induced Cre-mediated recombination during embryonic period, Frizzled9-CreER ${ }^{\mathrm{TM}}$; Rosa26-lacZ mice were given intraperitoneal-injected TM at E15.5 and harvested at P8. X-gal staining showed intense staining in the dentate gyrus and sparse staining in the cornu ammonis (CA) field (Fig. 8b), indicating recombination of Frizzled9-Cre in the embryonic hippocampus.

After TM induction at E15.5, the mutant DGs showed a considerable loss of FoxG1 at P5 (Fig. 8c). The morphology of mutant 
a
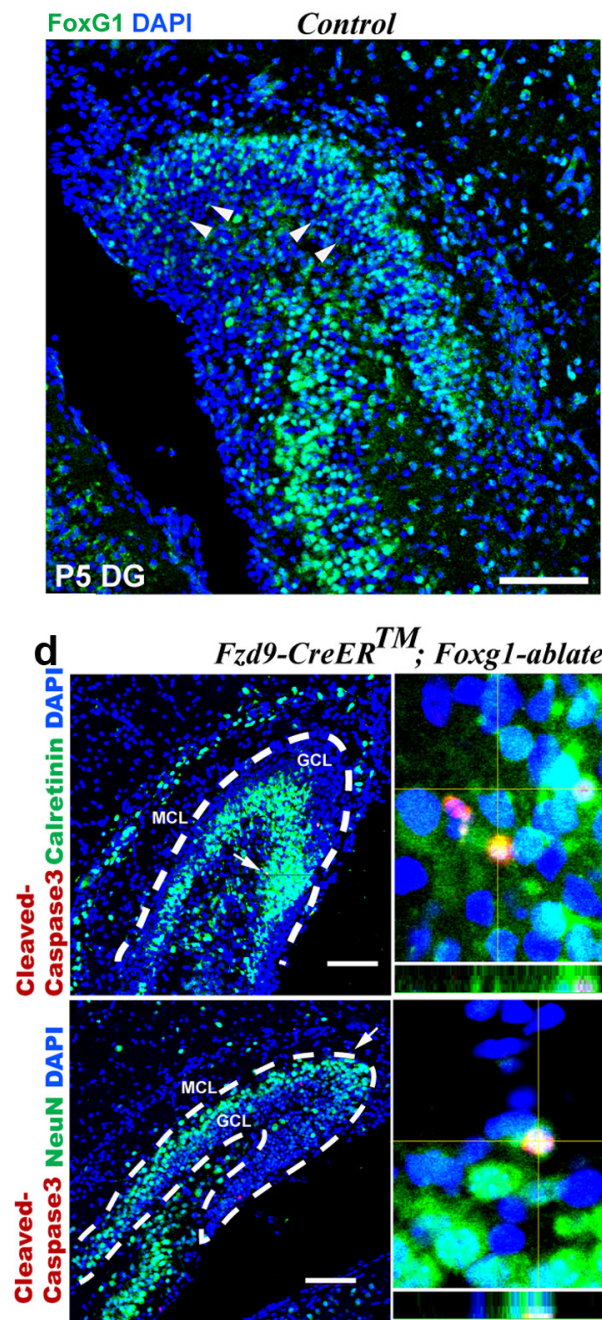

TM ; Foxg1-ablated

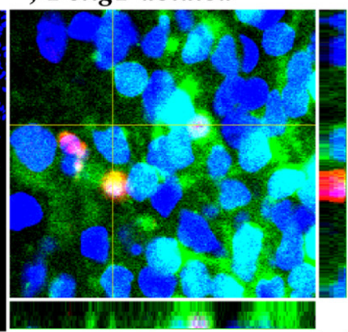

b

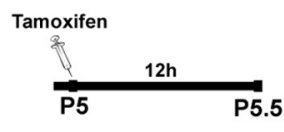

P5.5

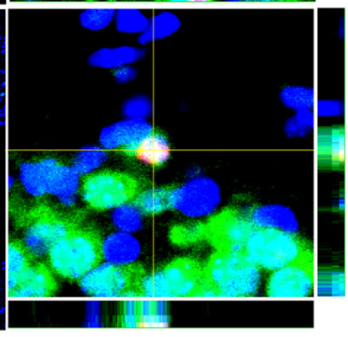

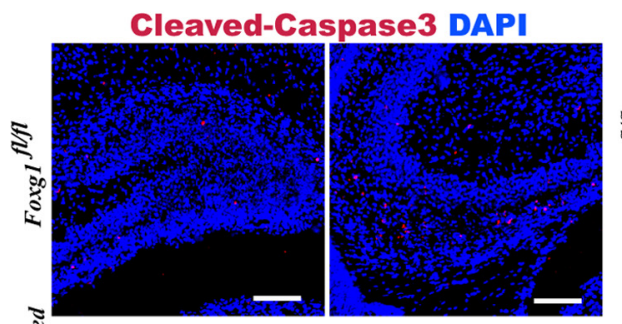

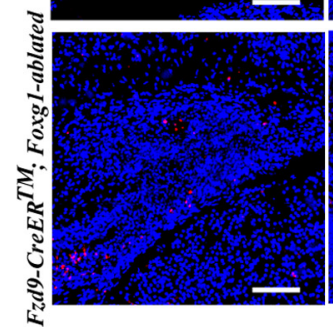

e
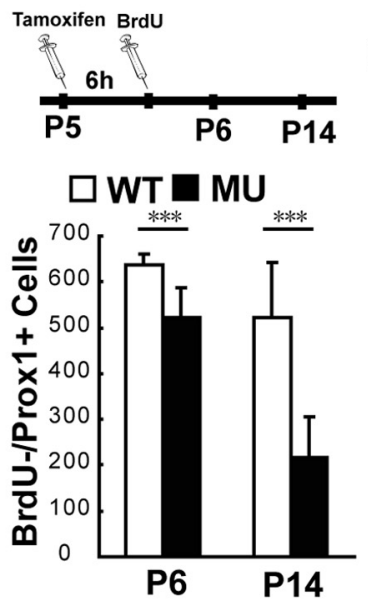

f
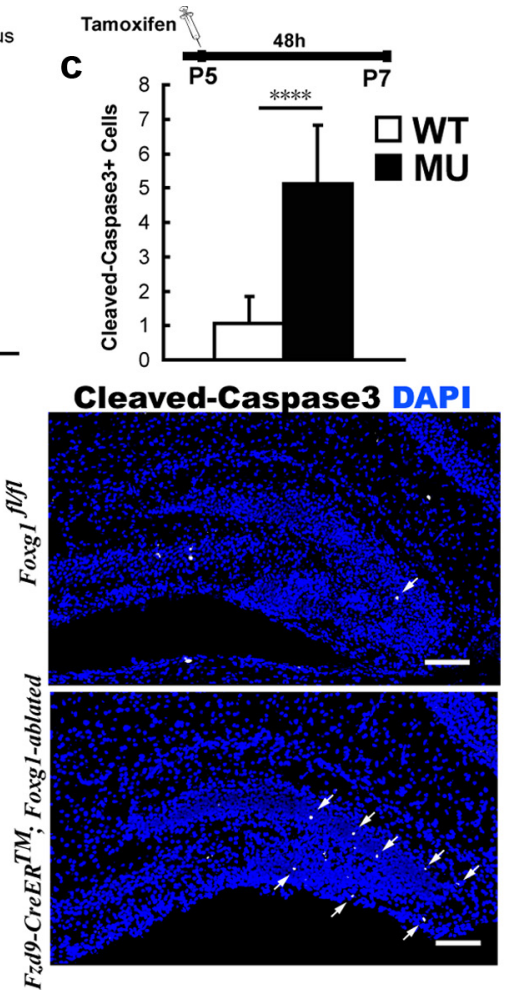

Calretinin DAPI
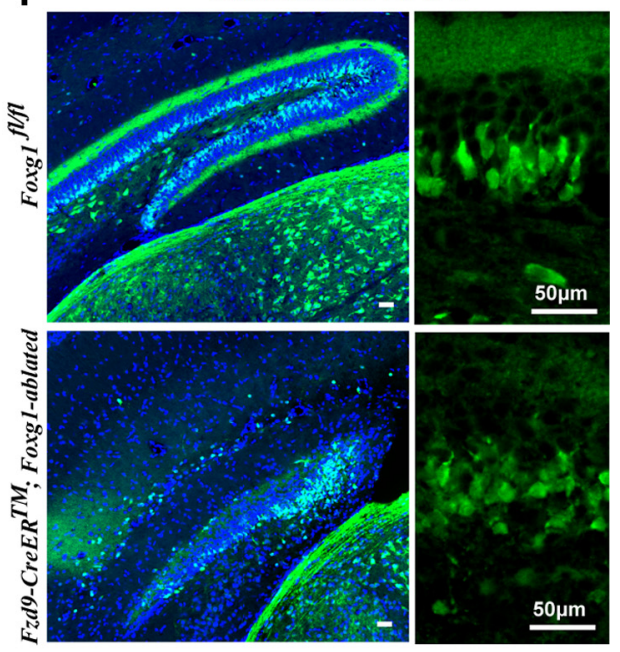

Figure 7. Foxg1 may be required for the survival and maturation of postmitotic neurons. Controls and Frizzled9-CreER ${ }^{\mathrm{TM}}$; Foxg $1^{\mathrm{fl} / \text { fl }}$ mice received TM treatment at P5. a, Stronger Foxg1 expression was detected in postmitotic neurons in P5 DG. $\boldsymbol{b}$, Increased cell death in mutant at P5.5 revealed by cleaved caspase-3. Top left, Schematic of TM injections. Top right and bottom, Increased cell death along the migratory streams from the dentate notch and in the DG $\left[n=3\right.$, WT; $n=3$, mutant (MU)]. c, Increased cell death in mutant DGs at P7 ( $n=3 ; 3$ ). $\boldsymbol{d}$, Cleaved caspase-3 ${ }^{+}$cells (red) were

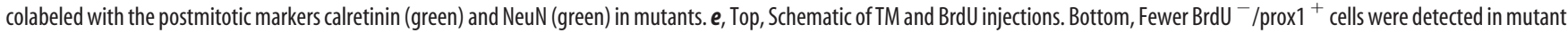
DGs at P6 and P14 $(n=3 ; 3) . f$, In mutant DGs, the band constituted by calretinin ${ }^{+}$axons of mossy cells was nearly absent. Calretinin ${ }^{+}$immature granule cells were scattered and did not extend long, parallel dendrites, suggesting a maturation defect. Histograms represent mean \pm SD. ${ }^{* *} p<0.005,{ }^{* * *} p<0.0005,{ }^{* * *} p<0.00005$, Student's $t$ test. Scale bars, $100 \mu m$.

DGs was not severally affected at P5, with the total area of DG remaining unchanged (Fig. $8 d$ ). However, each mutant DG became clearly longer on its vertical axis but shorter on its horizontal axis, accompanied by shorter suprapyramidal blades (Fig. $8 e$; $p<0.03$ ). To further evaluate possible changes, granule cellspecific marker proxl was used. We were surprised to find that, in P5 mutant DGs, prox ${ }^{+}$cells could still migrate to the dentate area with their number essentially unchanged (Fig. $8 g ; p=0.6939$ ), even though Foxg1 was deleted as early at E15.5. This result indicates that Foxg1 may not be crucial for the migration of primordial gran- ule cells. However, prox ${ }^{+}$cells did exhibit a problematic distribution pattern. In control DGs, prox $1^{+}$cells were concentrated in both suprapyramidal and infrapyramidal blades but scarce and scattered in the hilus, whereas in mutant DG prox ${ }^{+}$cells were inclined to be evenly distributed. At P14, the total area of each mutant DG evidently decreased (Fig. $8 d ; p<0.0002$ ), with a reduced length of both suprapyramidal blades and infrapyramidal blades (Fig. $8 e, f ; p<$ 0.008 and $p<9 \times 10^{-5}$, respectively).

We next turned to the radial glial scaffold, which could be labeled by GFAP. In mutant DGs at P5, the frame of the horse- 

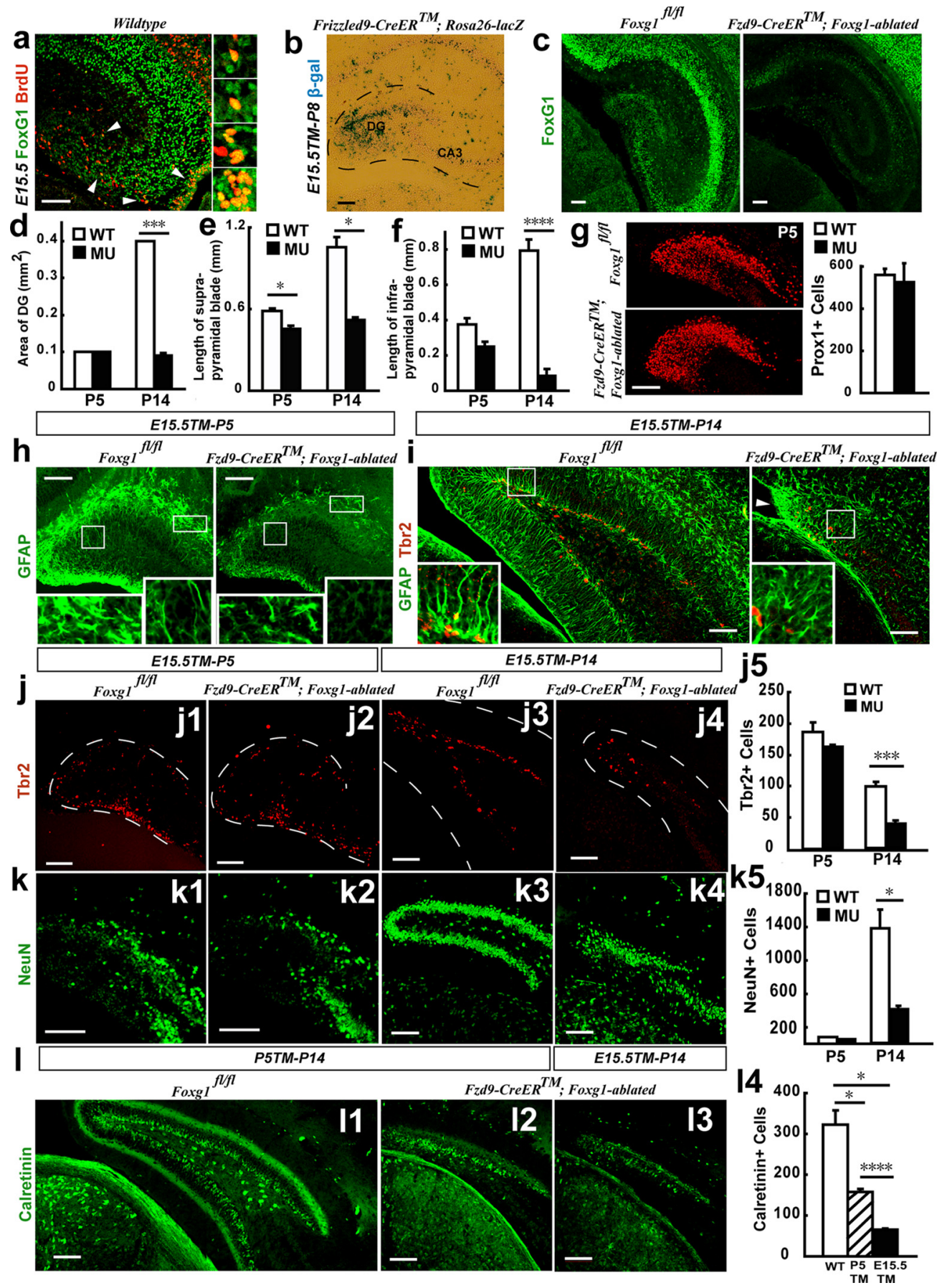

Figure 8. Little affected migration of primordial granule cells but severely disrupted secondary radial glial scaffold in the dentate gyrus after prenatal Foxg 1 ablation. $\boldsymbol{a}$, At E15.5, Foxg 1 strongly expressed in hippocampus VZ, but had a weaker immunoreactivity in dentate area. Arrowheads indicate massive colocalization of FoxG1 (green) with proliferating cells labeled by $1 \mathrm{~h}$ BrdU pulse injection (red). $\boldsymbol{b}$, X-gal staining of Frizzled9-CreER ${ }^{\text {TM}}$; Rosa26-lacZ mice at P8 after E15.5 TM induction. Staining was observed in CA field and dentate gyrus. $\boldsymbol{c}$, After TM induction at E15.5, mutant DG showed a considerable loss of FoxG1 at P5. $\boldsymbol{d}$, The total area of DG remained unchanged in mutant DGs at P5, but evidently decreased at P14 [n=3, WT; $n=3$, mutant (MU)]. $\boldsymbol{e}_{\text {, The }}$ suprapyramidal blades in mutant DGs reduced in length at P5 $(n=2 ; 2)$ and P14 $(n=3 ; 3) . \boldsymbol{f}$, The infrapyramidal blades in mutant DGs reduced in length at P14 $(n=3 ; 3) . \boldsymbol{g}$, Left, Prox ${ }^{+}$cells could still migrate to the dentate area at P5 in mutant DGs. However, in control DGs, prox $1^{+}$cells were concentrated in both suprapyramidal and infrapyramidal blades but scattered in hilus, whereas in mutant DGs, prox $1^{+}$cells tended to be distributed evenly. Right, The number of prox $1^{+}$cells was essentially unchanged $(n=2 ; 2) \cdot \boldsymbol{h}$, At P5, the frame of the horseshoe surrounding of GFAP ${ }^{+}$ process remains intact. However, the intensity of GFAP staining was significantly decreased in mutant DGs. Magnified graphs showed loss of secondary radial glial scaffold and decreased astrocytes in mutant DGs. $i$, At P14, controls have well established secondary radial glial scaffolds. By contrast, mutant DGs showed a complete loss of this structure. Magnified graphs showed complete loss of secondary radial glial scaffold in mutant DGs. j1, j2, At P5, Tbr2 ${ }^{+}$neural progenitors exhibited a relatively normal distribution pattern in mutant DGs. $j 3, j 4$, At P14, Tbr2 ${ }^{+}$cells were seriously disarrayed. $\mathbf{j} 5$, Absolute number of Tbr2 ${ }^{+}$cells slightly decreased with no statistical significance at P5 $(n=2 ; 2)$, but decreased dramatically at P14 $(n=3 ; 3) \cdot \mathbf{k} \mathbf{1}, \mathbf{k 2}$, At P5, NeuN ${ }^{+}$mature neurons exhibited a relatively normal distribution pattern in mutant DGs. $\mathbf{k} \mathbf{3}, \mathbf{k} \mathbf{4}$, At P14, the suprapyramidal blade was still visible in mutant DGs, although dramatically decreased in size. The infrapyramidal blade had almost vanished. $\boldsymbol{k} 5$, Absolute number of NeuN ${ }^{+}$cells slightly decreased with no statistical significance at P5 $(n=2 ; 2)$, but decreased dramatically at P14 ( $\left.n=3 ; 3\right) . / 1-I 4$, At P14, The absolute number of calretinin ${ }^{+}$immature neurons decreased $(n=3 ; 3)$. Compared to postnatal Foxg 1 ablation, prenatal deletion of Foxg 1 resulted in even fewer immature neurons. Histograms represent mean $\pm S D .{ }^{*} p<0.05,{ }^{* * *} p<0.0005,{ }^{* * * *} p<0.00005$, Student's $t$ test. Scale bars, $100 \mu \mathrm{m}$. 
shoe surrounding the $\mathrm{GFAP}^{+}$process remained. However, the intensity of GFAP staining significantly decreased (Fig. $8 h$ ). Since GFAP could also label the arising astrocytes at this stage, we considered the possibility of disturbed postnatal gliogenesis in mutant DGs. This result clearly contrasts with the increased astroglial lineage after postnatal Foxg1 ablation. However, considering that neurons are produced before astrocytes during development (Altman and Bayer, 1990; Subramanian et al., 2011), this result seems quite reasonable. At early embryonic stages, neuronal differentiation likely occurred on an accelerated timescale from Foxg1-null progenitor cells, led to depleted progenitor pool thereafter, and further resulted in diminished gliogenesis at postnatal stages, which should have been the peak time to produce glia. Possible accelerated neuron production also resulted in a statistically unchanged neuronal number at P5. At P14, in contrast to the well established secondary radial glial scaffold in control, mutant DGs showed a complete loss of this structure (Fig. 8 i). $\mathrm{GFAP}^{+}$cells in mutant DGs were mostly stellate-shaped astrocyte-like cells. Very few were highly branched radial glial cells. We observed an abnormal accumulation of $\mathrm{GFAP}^{+}$cells in the infrapyramidal blade (Fig. 8i, arrowhead), representing the impeded reorganization of radial glial cells. This is similar to what occurred with postnatal Foxg1 deletion.

We further detected the neuronal lineage in mutant DGs. At $\mathrm{P} 5, \mathrm{Tbr} 2^{+}$neural progenitors exhibited a relatively normal distribution pattern in mutant DGs (Fig. 8j1,j2). Their absolute numbers slightly decreased, with no statistical significance (Fig. $8 j 5 ; p=0.2869)$. However, at P14, Tbr2 ${ }^{+}$cells were seriously disarrayed and their absolute number decreased dramatically. (Fig. $8 j 3-j 5 ; p<3 \times 10^{-4}$ ). At P5, the pattern for mature $\mathrm{NeuN}^{+}$ neurons remained normal in mutant DGs but the number of these neurons slightly decreased. This decrease was not statistically significant (Fig. 8k1,k2,k5; $p=0.0769$ ). $\mathrm{NeuN}^{+}$cells decreased remarkably at P14 in mutant DGs compared to controls (Fig. $8 k 3-k 5 ; p<0.02$ ). Surprisingly, while the infrapyramidal blade in these mutant DGs had nearly vanished, the suprapyramidal blade was still visible, although dramatically smaller (Fig. $8 k 4)$. At P14, calretinin ${ }^{+}$immature neurons also decreased in their absolute number (Fig. 8l1,l3,14; $p<0.006$ ). Compared to postnatal Foxg1 ablation, prenatal deletion of Foxg1 resulted in even fewer immature neurons (Fig. 8l1-l4; $p<5 \times 10^{-6}$ between P5 TM and E15.5 TM), indicating more seriously depleted DG progenitors.

Together, these data suggest that Foxg1 activity, while perhaps not crucial for the migration of primordial granule cells and the formation of the suprapyramidal blade, is still indispensable for postnatal development. Prenatal deletion of Foxg1 leads to a more severe disruption of the DG progenitor pool and results in impaired postnatal gliogenesis, complete loss of secondary radial glial scaffold, and a greatly diminished infrapyramidal blade.

\section{Foxg1 may be involved in Reelin signaling to regulate postnatal dentate gyrus development}

Foxg1 ablation leads to a reeler-like phenotype

In Reelin-deficient reeler mice, the hippocampal radial glial scaffold fails to form, leading to defective migration of granule cells (Förster et al., 2002; Frotscher et al., 2003; Weiss et al., 2003). In the reeler DG, there are excessive astrocytes resulting from premature astrocytic differentiation of radial glial cells (Fig. 9a), and granule cells are scattered throughout the DG (Fig. 9b). A decreased cell proliferation was also found in the DG of reeler mutants (Fig. 9c), which could be explained by an early exhaustion of radial glial cells (Zhao et al., 2007).
Our results demonstrate a disrupted radial glial scaffold in Foxg1-ablated mice (Fig. 3). In these mice, granule cells fail to migrate properly and to form a compact GL. Instead, these cells were evenly distributed in the hilus (Fig. 2c). Foxg1 ablation also drove radial glial cells to transition into astrocytes (Fig. 6). This pattern along with defective cell proliferation (Fig. 5) makes the characteristics of these phenotypes, occurring postnatally after Foxg1 deletion, highly consistent with those observed previously in reeler mice, indicating possible cross talk between these two genes.

\section{Foxg1 expression is reduced in the DG of reeler mutants}

To study the role of Foxg1 in Reelin-dependent radial glia formation in the DG, we analyzed Foxg1 activation in the reeler mouse. Immunostaining suggested an evident decrease of FoxG1 in reeler DG (Fig. 9d). Western blot analysis was conducted in P14 reeler DGs, FoxG1 levels were significantly reduced in the reeler DGs compared with that of wild-type animals (Fig. 9f; $N>3$ ). However, in the reeler neocortex, we were unable to observe such severe downregulation of FoxG1 (Fig. 9e). After birth, when the radial glial scaffold in the neocortex stops neuron production and turns to astrocytic differentiation, hippocampal radial glia is undergoing rapid self-renewal and neurogenesis. The asynchronism of radial glial development between cortex and hippocampus could possibly explain this discrepancy. Surprisingly, reeler DGs showed normal levels of Foxg1 mRNA (Fig. 9g; $p=0.755$ ). These results strongly suggest that Foxg1 is normally transcribed in reeler DGs, but may later undergo degradation on the protein level. Further study is needed to elucidate the mechanism.

\section{FoxG1 and Reelin colocalize in the DG}

Reelin, an extracellular matrix molecule, is expressed by Cajal Retzius cells in the cortex and dentate gyrus (Hirotsune et al., 1995; D'Arcangelo et al., 1997; Curran and D'Arcangelo, 1998; Rice et al., 1998). Here we show that FoxG1 and Reelin are colocalized near the hippocampal MZ (Fig. $9 h$, arrowheads). This result indicates that Foxg1 is not only expressed in cells that receive secreted Reelin, but is also expressed directly in those Reelin-secreting Cajal Retzius cells. Interestingly, in Frizzled9CreER $^{\mathrm{TM}}$; Foxg1-ablated mice, Reelin ${ }^{+} /$calretinin $^{+}$cells, which are likely Cajal Retzius cells, were increased in the MZ of the DG (Fig. 9i, arrows). Reelin mRNA had a twofold corresponding elevation in Foxg1-null DGs (Fig. 9j; $p=0.033$ ). We can infer that Foxg1 may act as a downstream factor of Reelin contributing to the formation of the radial glial scaffold. Downregulation of Foxg1 in those Reelin-secreting cells, however, may initiate a negative regulatory feedback to produce more Reelin ${ }^{+}$cells, although the increased number of Reelin ${ }^{+} /$calretinin $^{+}$cells may not compensate for the severe abnormality caused by Foxg1 ablation.

\section{Discussion}

In this study, we report the functional roles of Foxg1 in the DG at prenatal and early postnatal stages. A possible working mechanism for Foxg1 in postnatal DG development was illustrated (Fig. 10). Inactivation of Foxg1 leads to a loss of the SGZ and remarkable malformation of the DG. The numbers of NSCs and IPCs in the DG were reduced, possibly due to the failure of self-renewal and to overdifferentiation. Meanwhile, because of the role of the radial glial scaffold of DG NSCs, loss of these cells resulted in a migration defect. Lack of Foxg1 promoted both gliogenesis and neurogenesis and led to a relatively increased number of astro- 


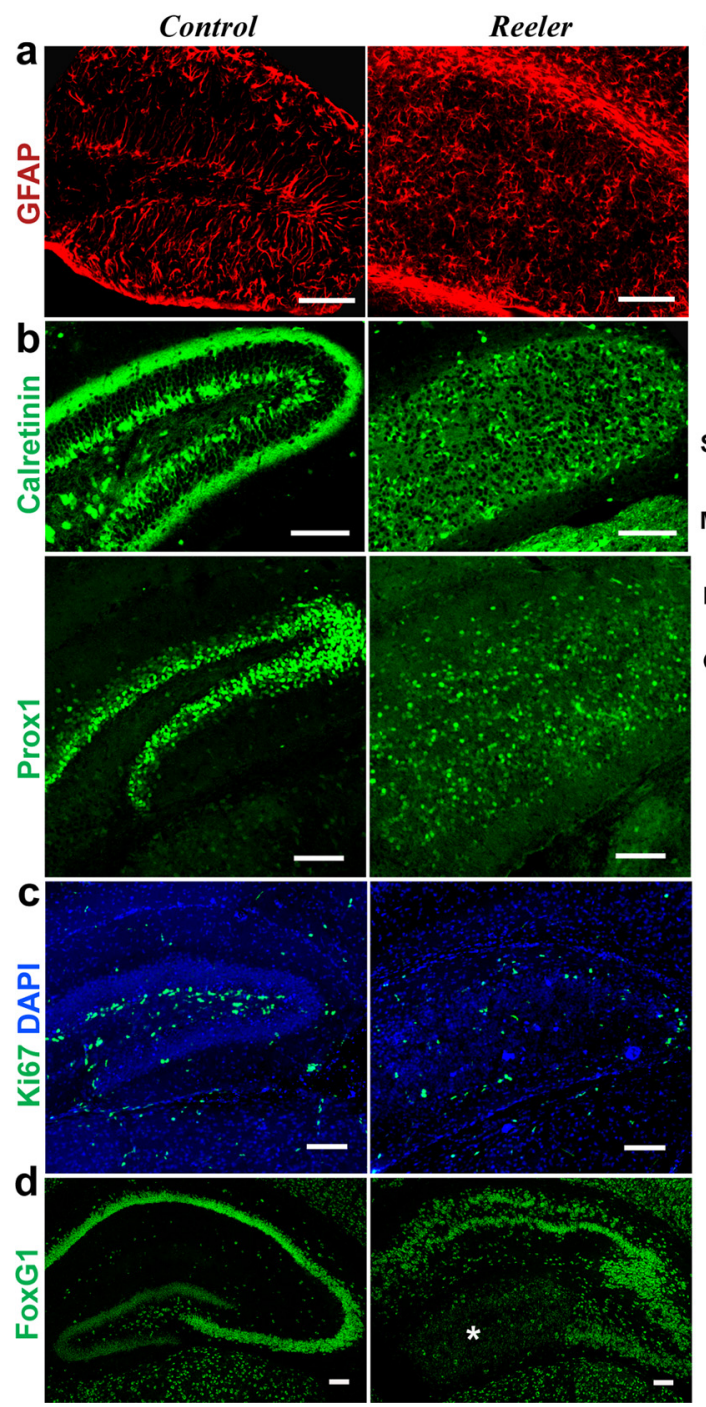

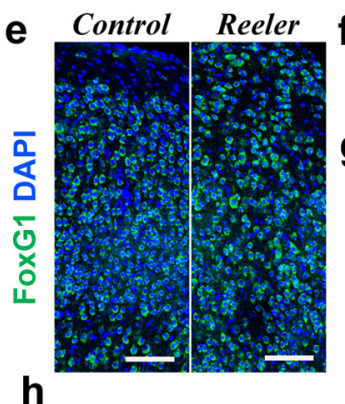

h
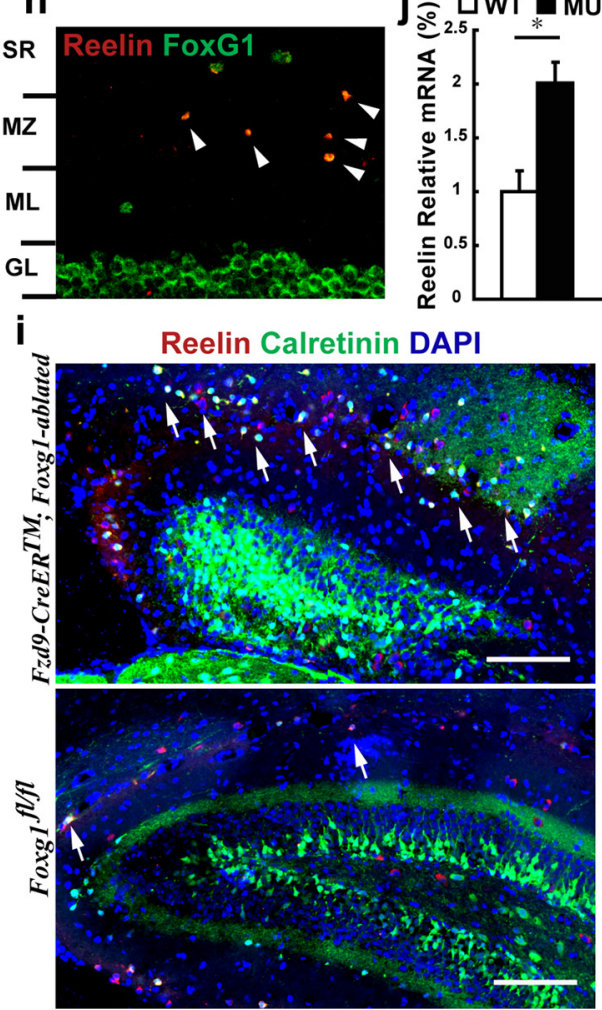

Figure 9. Foxg1 may cooperate with Reelin to regulate postnatal dentate gyrus development. $\boldsymbol{a}$, Excessive astrocytes were observed in the reeler hippocampus. $\boldsymbol{b}$, Calretinin ${ }^{+}$and prox $1^{+}$granule cells were scattered throughout the reeler DG. $c$, Decreased cell proliferation shown by reduced Ki67 ${ }^{+}$cells in the DG of reeler mutants. $\boldsymbol{d}$, Immunostaining of FoxG1 expression in P14 reeler and wild-type hippocampus. Mutant DGs had a significant lower staining density of FoxG1.e, Severe downregulation of FoxG1 was not observed in the neocortex of reeler. $\boldsymbol{f}$, Western blot analysis of FoxG1. Protein levels were significantly reduced in reeler DGs compared with wild-type animals $(n=3, \mathrm{WT} ; n=3, \mathrm{MU})$. $\boldsymbol{g}$, reeler DGs showed normal levels of Foxg1 mRNA $(n=2 ; 3)$. $\boldsymbol{h}$, FoxG1 and Reelin coimmunostaining of P7 wild-type hippocampus. Arrowheads show colocalization of FoxG1 and Reelin in cells located near hippocampal MZ. i, Calretinin and Reelin coimmunostaining of P14 controls and the Frizzled9-CreER ${ }^{\mathrm{TM}}$ brain. Reelin ${ }^{+} /$calretinin $^{+}$cells, likely Cajal Retzius cells, were increased in the MZ of the Foxg1-ablated DG. $\boldsymbol{j}$, Reelin mRNA had a twofold elevation in Foxg 1-null DGs $(n=2 ; 3)$. Histograms represent mean \pm SD. ${ }^{*} p<0.05$, Student's $t$ test. Scale bars, $100 \mu \mathrm{m}$. SR, Stratum radiatum.

cytes. The final neuronal output, however, was reduced, probably due to massive apoptosis.

Nevertheless, in Frizzled9-CreER ${ }^{\mathrm{TM}}$; Foxg $1^{\mathrm{fl} / \mathrm{fl}}$ mice, Foxg1 was actually deleted in each cell type simultaneously. Thus, although it seems that Foxg1 exerts different effects on DG cell subtypes, we cannot assert a cell intrinsic function of Foxg1 in each cell type. It is entirely possible that the overdifferentiation of NSCs or IPCs was a response to compensate for increased cell death, or vice versa. Further studies are needed to answer this question directly.

Foxg1 has a crucial role in postnatal reorganization of dentate precursor and granule cells

At birth, the hilus is filled with mixed newly born neurons and precursors. During the first postnatal week, this rather amorphous mass undergoes a conversion into a highly radially organized structure. This reorganization is apparently important for the continuing generation and proper distribution of granule cells. Our results suggest that Foxg1 may have a significant involvement in this reorganization process. Postnatal deletion of Foxg1 severely impaired the formation of the SGZ. The secondary radial glial scaffold was disrupted, resulting in improper distribution of dentate progenitors and granule cells. Prenatal deletion of Foxg1 caused a minor disruption at P5, but led to a complete loss of the secondary radial glial scaffold and to migration disturbance of dentate progenitors and granule cells at P14. This result further demonstrates that the reorganization process is of significant importance during postnatal DG development. Foxg1 inactivation during this period greatly aggravates the phenotype in mutant DGs.

Although Foxg1 ablation caused a nearly complete loss of infrapyramidal blade, the suprapyramidal blade could partially develop regardless of the deletion time of Foxg1. These results suggest that the suprapyramidal blade and the infrapyramidal 


\section{Wildtype}
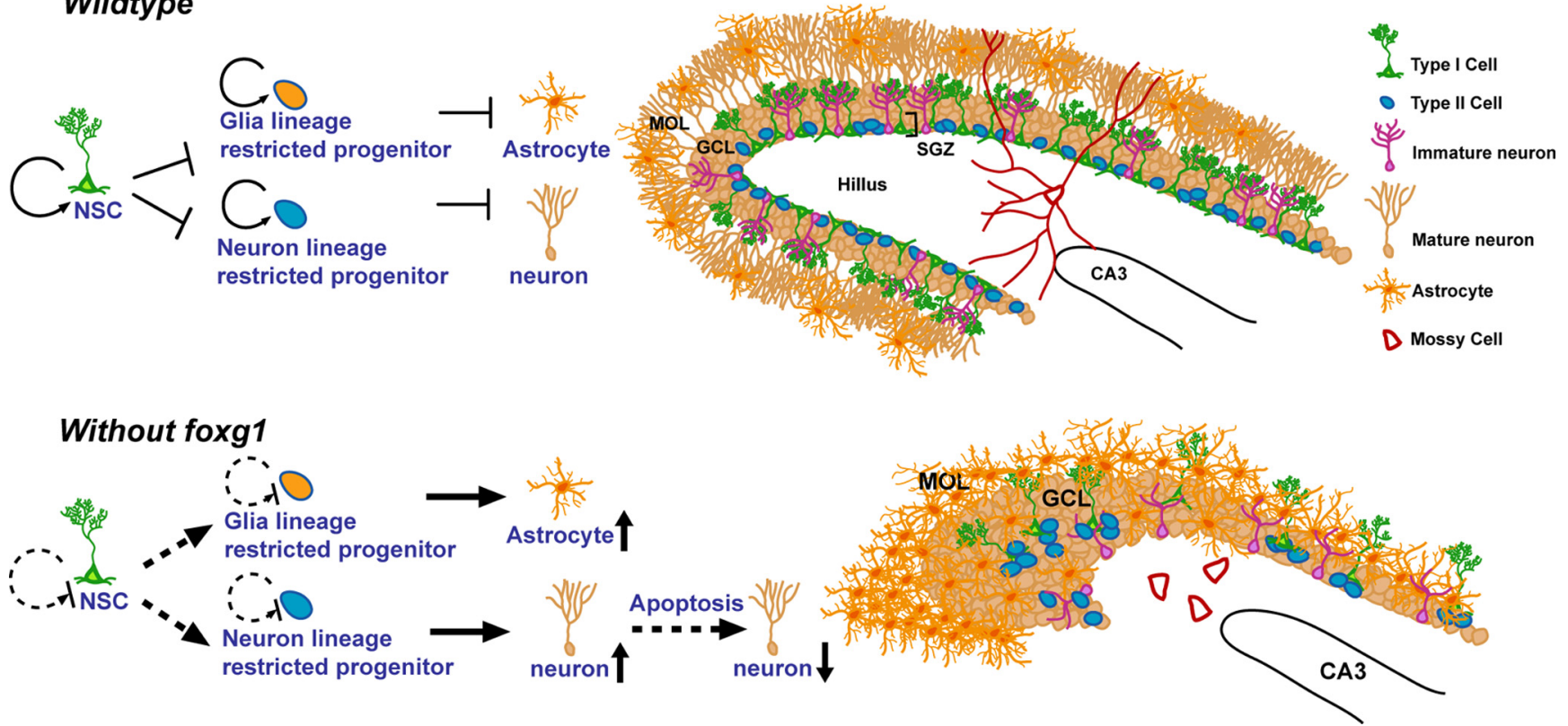

Figure 10. Hypothetical model of Foxg 7 function in postnatal hippocampus development. Top, In normal dentate gyrus, NSCs and progenitors keep proliferating, maintaining normal progenitor pool. The somata of NSCs and IPCs are confined within SGZ, while the unbranched radial processes of NSCs extend through GL and serve as scaffold for neuron migration. Bottom, Inactivation of Foxg 1 leads to a loss of the SGZ and remarkable malformation of the DG. The numbers of NSCs and IPCs in the DG were reduced, possibly due to the failure of self-renewal and to overdifferentiation (we assume this to be a cell intrinsic effect and therefore use only dash lines). Meanwhile, because of the role of the radial glial scaffold of DG NSCs, loss of these cells resulted in a migration defect. Lack of Foxg 1 promoted both gliogenesis and neurogenesis and led to an increased relative number in DG astrocytes. The final neuronal output, however, was reduced, probably due to massive apoptosis (cell intrinsic role needs to be verified).

blade may each have its own distinct developmental strategy. Possibly, cells that form the suprapyramidal blade migrate to the primordial dentate area at an early stage and require little Foxg1 function, while the postnatal formation of the infrapyramidal blade requires the Foxg1 function to enable the more complex reorganization of progenitors.

\section{Foxg1 promotes progenitor self-renewal and inhibits both neurogenesis and gliogenesis}

We demonstrate that Foxg1 inactivation in NSCs and IPCs leads to a decrease in the size of these compartments and an overproduction of neurons and astrocytes. Our hypothesis from these results is that Foxg1 is a critical factor controlling the balance between progenitor self-renewal and differentiation. In IPCs, the loss of Foxg1 may enhance their differentiation toward neurons. In NSCs, the loss of Foxg1 might similarly drive these cells to differentiate toward their progeny as IPCs and astrocytes. Because NSCs are the only type of progenitor that can produce astrocytes in the DG, it is reasonable to infer that the increased numbers of astrocytes were generated from NSCs. Although increased numbers of neurons were observed at $\mathrm{P} 7$, we do not have evidence showing increased generation of IPCs from NSCs. One likely reason for this lack of evidence is that the transient increase in IPC generation is rapidly followed by their differentiation into neurons, which is likely when we consider the dynamic changes of the DG cellular compartments (Fig. $4 b, c$ ): NSCs dramatically decreased immediately at P7, but IPCs did not show a significant reduction until P14.

It has been reported that the overexpression of Foxg1 in NSCs in vitro leads to a blockade of glial fate (Shen et al., 2006; Mondal et al., 2007; Brancaccio et al., 2010). The most recent experiments conducted on cultured cortical neural precursors led to the conclusion that Foxg1 inhibits gliogenesis and pro- motes neurogenesis (Brancaccio et al., 2010). However, in those experiments, neuron and astroglia differentiation were actually correlated. Foxg1 overexpression dramatically antagonizes the NSC-to-early glia progenitor (eGP) transition and the subsequent eGP-to-late glia progenitor progression. However, the NSC-to-early neuron transition (NSC-born) index and the NSC-to-early neuronal progenitor index were also downregulated by excessive Foxg1, although these effects were not as severe as the effect of excessive Foxg1 on the NSC-toeGP transition index. We believe that this discrepancy is possibly due to reduced cell death of postmitotic neurons exerted by Foxg1 overexpression, which masked the blockade of neurogenesis. In addition, studies conducted by these colleagues demonstrated that when NSCs overexpressing Foxg1 were transferred to differentiation-permissive conditions in vitro, the number of astrocytes was halved, while neuron frequency was not affected. If Foxg1 exerts an antigliogenesis/proneurogenesis effect, a longer culture time may cause the reduction of astrocytes and a more pronounced increase in the number of neurons. However, when culture time was doubled, neuron frequency was upregulated, while the reduction of glial frequencies was less pronounced. The changing frequencies of astrocytes and neurons are not in conflict but are in accord. Similarly, in our results, BrdU birthdating of mutant DGs demonstrated an increase in newborn astrocytes and newborn neurons. The ratios of $\mathrm{BrdU}^{+} / \mathrm{GFAP}^{+}$astrocytes and $\mathrm{BrdU}^{+} /$ prox $1^{+}$neurons among the total $\mathrm{BrdU}^{+}$cells were both elevated, perhaps at the expense of $\mathrm{BrdU}^{+}$progenitors. We therefore hypothesize that Foxg1 suppresses both neuronal and glial differentiation rather than being solely antigliogenic.

This hypothesis is further supported by the decreased GFAP staining intensity observed at P5 after E15.5 deletion of Foxg1. If Foxg1 exerts only an antigliogenic effect, then, when it was deleted at the embryonic stage, which generates mainly 
neurons, we should have been able to observe a premature production of astrocytes from progenitors that would otherwise produce neurons. However, we did not find obvious increased astrocytes in the embryonic dentate gyrus, but instead we found decreased astrocytes postnatally due to depletion of progenitors, which was possibly caused by advanced neurogenesis prenatally.

\section{Foxg1 may stimulate postmitotic neuron survival}

Previous studies of constitutive Foxg1 ${ }^{+/-}$mice reported no direct evidence of cell death in the DG (Shen et al., 2006). In this study, we report an increased number of dead cells in the Foxg1deleted DG. Through detailed analysis, we revealed these dead cells to be postmitotic neurons. These findings suggest that Foxg1 may be required for postmitotic neuron survival, and may elucidate the role of the strong expression of Foxg1 in postmitotic cells. However, the cell intrinsic role of Foxgl in postmitotic cells needs to be verified.

\section{Foxg1 may be involved in Reelin signaling to regulate dentate gyrus development}

In our study, we show that Foxg1 ablation can reproduce defects similar to those seen in reeler mice, and FoxG1 was found downregulated in the reeler DGs. The correlation between Foxg1 and Reelin signaling may indicate possible cross talk between these two signaling pathways. It is possible that Foxg1 is involved in the Reelin signaling pathway, probably as a downstream factor, maintaining the undifferentiated status of radial glial cells. We additionally found that Foxg1 ablation can result in increased Reelin $^{+} /$calretinin ${ }^{+}$cells in the MZ of the DG. Considering the colocalization of these two genes near the hippocampal MZ, the increased Reelin ${ }^{+} /$calretinin $^{+}$cells could be a consequence of negative regulatory feedback initiated by deleted Foxg1.

Signaling cross talk between Reelin and Notch has been recently identified (Hashimoto-Torii et al., 2008; Sibbe et al., 2009). In the reeler dentate gyrus, reduced Notch1 signaling was found, and inhibition of Notch signaling in organotypic hippocampal slice cultures induced a reeler-like phenotype. Moreover, inhibition of Notch activation could block Reelin-dependent rescue of the reeler phenotype. Meanwhile, the involvement of Foxg1 in Notch signaling has been gradually revealed. It has been demonstrated that Foxg1 is able to form a transcriptional repressor complex with Hairy/Enhancer of split 1 (Hes1) in a Grouchodependent manner (Yao et al., 2001), while this complexes could in response to Notch activation (Grbavec et al., 1998; McLarren et al., 2001). Since Hes 1 and Hes5 had been proved to maintain the undifferentiated state of neural stem cells in the embryonic telencephalon (Ohtsuka et al., 2001), it is likely that Foxg1 acts through the Hes family in keeping the balance of self-renewal and differentiation of NSCs. Although Hes 5 was believed to promote gliogenesis in mouse retina (Hojo et al., 2000), the gene may only secondarily promote astrocyte development by maintaining neural stem cells until astrocytic differentiation occurs. In other words, the fundamental function of Hes family is to arrest NSCs in an undifferentiating status, which is in accord with Foxgl function generalized from our results. Together, we raise a hypothetical model in which Reelin acts through Foxg1 and finally through Notch signaling, leading to a premature differentiation of progenitors. Further studies confirming the direct interaction between Reelin and Foxg1 are needed.

\section{References}

Aimone JB, Wiles J, Gage FH (2006) Potential role for adult neurogenesis in the encoding of time in new memories. Nat Neurosci 9:723-727.

Altman J (1962) Are new neurons formed in the brains of adult mammals? Science 135:1127-1128.

Altman J, Bayer SA (1990) Prolonged sojourn of developing pyramidal cells in the intermediate zone of the hippocampus and their settling in the stratum pyramidale. J Comp Neurol 301:343-364.

Altman J, Das GD (1965) Autoradiographic and histological evidence of postnatal hippocampal neurogenesis in rats. J Comp Neurol 124:319-335.

Anthony TE, Heintz N (2008) Genetic lineage tracing defines distinct neurogenic and gliogenic stages of ventral telencephalic radial glial development. Neural Dev 3:30.

Ariani F, Hayek G, Rondinella D, Artuso R, Mencarelli MA, Spanhol-Rosseto A, Pollazzon M, Buoni S, Spiga O, Ricciardi S, Meloni I, Longo I, Mari F, Broccoli V, Zappella M, Renieri A (2008) FOXG1 is responsible for the congenital variant of Rett syndrome. Am J Hum Genet 83:89-93.

Bakker A, Kirwan CB, Miller M, Stark CE (2008) Pattern separation in the human hippocampal CA3 and dentate gyrus. Science 319:1640-1642.

Bedogni F, Hodge RD, Elsen GE, Nelson BR, Daza RA, Beyer RP, Bammler TK, Rubenstein JL, Hevner RF (2010) Tbrl regulates regional and laminar identity of postmitotic neurons in developing neocortex. Proc Natl Acad Sci U S A 107:13129-13134.

Böhmer AE, Oses JP, Schmidt AP, Perón CS, Krebs CL, Oppitz PP, D’Avila TT, Souza DO, Portela LV, Stefani MA (2011) Neuron-specific enolase, S100B, and glial fibrillary acidic protein levels as outcome predictors in severe traumatic brain injury patients. Neurosurgery 68:1624-1630.

Bonfanti L, Peretto P (2007) Radial glial origin of the adult neural stem cells in the subventricular zone. Prog Neurobiol 83:24-36.

Brancaccio M, Pivetta C, Granzotto M, Filippis C, Mallamaci A (2010) Emx2 and Foxg1 inhibit gliogenesis and promote neuronogenesis. Stem Cells 28:1206-1218.

Brunne B, Zhao S, Derouiche A, Herz J, May P, Frotscher M, Bock HH (2010) Origin, maturation, and astroglial transformation of secondary radial glial cells in the developing dentate gyrus. Glia 58:1553-1569.

Chiang YH, Silani V, Zhou FC (1996) Morphological differentiation of astroglial progenitor cells from EGF-responsive neurospheres in response to fetal calf serum, basic fibroblast growth factor, and retinol. Cell Transplant 5:179-189.

Crespel A, Coubes P, Rousset MC, Alonso G, Bockaert J, Baldy-Moulinier M, Lerner-Natoli M (2002) Immature-like astrocytes are associated with dentate granule cell migration in human temporal lobe epilepsy. Neurosci Lett 330:114-118.

Curran T, D'Arcangelo G (1998) Role of reelin in the control of brain development. Brain Res Brain Res Rev 26:285-294.

D’Arcangelo G, Nakajima K, Miyata T, Ogawa M, Mikoshiba K, Curran T (1997) Reelin is a secreted glycoprotein recognized by the CR-50 monoclonal antibody. J Neurosci 17:23-31.

Dasgupta B, Gutmann DH (2005) Neurofibromin regulates neural stem cell proliferation, survival, and astroglial differentiation in vitro and in vivo. J Neurosci 25:5584-5594.

Deng W, Saxe MD, Gallina IS, Gage FH (2009) Adult-born hippocampal dentate granule cells undergoing maturation modulate learning and memory in the brain. J Neurosci 29:13532-13542.

Deng W, Aimone JB, Gage FH (2010) New neurons and new memories: how does adult hippocampal neurogenesis affect learning and memory? Nat Rev Neurosci 11:339-350.

Eckenhoff MF, Rakic P (1984) Radial organization of the hippocampal dentate gyrus: a Golgi, ultrastructural, and immunocytochemical analysis in the developing rhesus monkey. J Comp Neurol 223:1-21.

Ekmark-Lewén S, Lewén A, Israelsson C, Li GL, Farooque M, Olsson Y, Ebendal T, Hillered L (2010) Vimentin and GFAP responses in astrocytes after contusion trauma to the murine brain. Restor Neurol Neurosci 28:311-321.

Elmi M, Matsumoto Y, Zeng ZJ, Lakshminarasimhan P, Yang W, Uemura A, Nishikawa S, Moshiri A, Tajima N, Agren H, Funa K (2010) TLX activates MASH1 for induction of neuronal lineage commitment of adult hippocampal neuroprogenitors. Mol Cell Neurosci 45:121-131.

Englund C, Fink A, Lau C, Pham D, Daza RA, Bulfone A, Kowalczyk T, Hevner RF (2005) Pax6, Tbr2, and Tbr1 are expressed sequentially by 
radial glia, intermediate progenitor cells, and postmitotic neurons in developing neocortex. J Neurosci 25:247-251.

Filippov V, Kronenberg G, Pivneva T, Reuter K, Steiner B, Wang LP, Yamaguchi M, Kettenmann H, Kempermann G (2003) Subpopulation of nestin-expressing progenitor cells in the adult murine hippocampus shows electrophysiological and morphological characteristics of astrocytes. Mol Cell Neurosci 23:373-382.

Förster E, Tielsch A, Saum B, Weiss KH, Johanssen C, Graus-Porta D, Müller U, Frotscher M (2002) Reelin, Disabled 1, and beta 1 integrins are required for the formation of the radial glial scaffold in the hippocampus. Proc Natl Acad Sci U S A 99:13178-13183.

Frotscher M, Haas CA, Förster E (2003) Reelin controls granule cell migration in the dentate gyrus by acting on the radial glial scaffold. Cereb Cortex 13:634-640.

Ganat YM, Silbereis J, Cave C, Ngu H, Anderson GM, Ohkubo Y, Ment LR, Vaccarino FM (2006) Early postnatal astroglial cells produce multilineage precursors and neural stem cells in vivo. J Neurosci 26:8609-8621.

Grbavec D, Lo R, Liu Y, Stifani S (1998) Transducin-like Enhancer of split 2, a mammalian homologue of Drosophila Groucho, acts as a transcriptional repressor, interacts with Hairy/Enhancer of split proteins, and is expressed during neuronal development. Eur J Biochem 258:339-349.

Gregg C, Weiss S (2003) Generation of functional radial glial cells by embryonic and adult forebrain neural stem cells. J Neurosci 23:11587-11601.

Gu Y, Janoschka S, Ge S (2011) Studying the integration of adult-born neurons. J Vis Exp 49:2548.

Hanashima C, Shen L, Li SC, Lai E (2002) Brain factor-1 controls the proliferation and differentiation of neocortical progenitor cells through independent mechanisms. J Neurosci 22:6526-6536.

Hartfuss E, Galli R, Heins N, Götz M (2001) Characterization of CNS precursor subtypes and radial glia. Dev Biol 229:15-30.

Hashimoto-Torii K, Torii M, Sarkisian MR, Bartley CM, Shen J, Radtke F, Gridley T, Sestan N, Rakic P (2008) Interaction between Reelin and Notch signaling regulates neuronal migration in the cerebral cortex. Neuron 60:273-284.

Hébert JM, McConnell SK (2000) Targeting of cre to the Foxg1 (BF-1) locus mediates loxP recombination in the telencephalon and other developing head structures. Dev Biol 222:296-306.

Heiman M, Schaefer A, Gong S, Peterson JD, Day M, Ramsey KE, SuárezFariñas M, Schwarz C, Stephan DA, Surmeier DJ, Greengard P, Heintz N (2008) A translational profiling approach for the molecular characterization of CNS cell types. Cell 135:738-748.

Helms AW, Battiste J, Henke RM, Nakada Y, Simplicio N, Guillemot F, Johnson JE (2005) Sequential roles for Mash1 and Ngn2 in the generation of dorsal spinal cord interneurons. Development 132:2709-2719.

Hirotsune S, Takahara T, Sasaki N, Hirose K, Yoshiki A, Ohashi T, Kusakabe M, Murakami Y, Muramatsu M, Watanabe S (1995) The reeler gene encodes a protein with an EGF-like motif expressed by pioneer neurons. Nat Genet 10:77-83.

Hodge RD, Kowalczyk TD, Wolf SA, Encinas JM, Rippey C, Enikolopov G, Kempermann G, Hevner RF (2008) Intermediate progenitors in adult hippocampal neurogenesis: Tbr2 expression and coordinate regulation of neuronal output. J Neurosci 28:3707-3717.

Hojo M, Ohtsuka T, Hashimoto N, Gradwohl G, Guillemot F, Kageyama R (2000) Glial cell fate specification modulated by the bHLH gene Hes5 in mouse retina. Development 127:2515-2522.

Holmes MM, Galea LA, Mistlberger RE, Kempermann G (2004) Adult hippocampal neurogenesis and voluntary running activity: circadian and dose-dependent effects. J Neurosci Res 76:216-222.

Jessberger S, Clark RE, Broadbent NJ, Clemenson GD Jr, Consiglio A, Lie DC, Squire LR, Gage FH (2009) Dentate gyrus-specific knockdown of adult neurogenesis impairs spatial and object recognition memory in adult rats. Learn Mem 16:147-154.

Kempermann G, Kuhn HG, Gage FH (1997a) More hippocampal neurons in adult mice living in an enriched environment. Nature 386:493-495.

Kempermann G, Kuhn HG, Gage FH (1997b) Genetic influence on neurogenesis in the dentate gyrus of adult mice. Proc Natl Acad Sci U S A 94:10409-10414.

Kempermann G, Wiskott L, Gage FH (2004) Functional significance of adult neurogenesis. Curr Opin Neurobiol 14:186-191.

Kimura N, Nakashima K, Ueno M, Kiyama H, Taga T (1999) A novel mammalian T-box-containing gene, Tbr2, expressed in mouse developing brain. Brain Res Dev Brain Res 115:183-193.
Kornack DR, Rakic P (2001) Cell proliferation without neurogenesis in adult primate neocortex. Science 294:2127-2130.

Kortüm F, Das S, Flindt M, Morris-Rosendahl DJ, Stefanova I, Goldstein A, Horn D, Klopocki E, Kluger G, Martin P, Rauch A, Roumer A, Saitta S, Walsh LE, Wieczorek D, Uyanik G, Kutsche K, Dobyns WB (2011) The core FOXG1 syndrome phenotype consists of postnatal microcephaly, severe mental retardation, absent language, dyskinesia, and corpus callosum hypogenesis. J Med Genet 48:396-406.

Leutgeb JK, Leutgeb S, Moser MB, Moser EI (2007) Pattern separation in the dentate gyrus and CA3 of the hippocampus. Science 315:961-966.

Li G, Pleasure SJ (2005) Morphogenesis of the dentate gyrus: what we are learning from mouse mutants. Dev Neurosci 27:93-99.

Li Y, Tian C, Yang Y, Yan Y, Ni Y, Wei Y, Pleasure SJ, Zhao C (2011) An inducible transgenic Cre mouse line for the study of hippocampal development and adult neurogenesis. Genesis 49:919-926.

Lie DC, Colamarino SA, Song HJ, Désiré L, Mira H, Consiglio A, Lein ES, Jessberger S, Lansford H, Dearie AR, Gage FH (2005) Wnt signalling regulates adult hippocampal neurogenesis. Nature 437:1370-1375.

McLarren KW, Theriault FM, Stifani S (2001) Association with the nuclear matrix and interaction with Groucho and RUNX proteins regulate the transcription repression activity of the basic helix loop helix factor Hes1. J Biol Chem 276:1578-1584.

McManus MF, Chen LC, Vallejo I, Vallejo M (1999) Astroglial differentiation of cortical precursor cells triggered by activation of the cAMPdependent signaling pathway. J Neurosci 19:9004-9015.

Mencarelli MA, Spanhol-Rosseto A, Artuso R, Rondinella D, De Filippis R, Bahi-Buisson N, Nectoux J, Rubinsztajn R, Bienvenu T, Moncla A, Chabrol B, Villard L, Krumina Z, Armstrong J, Roche A, Pineda M, Gak E, Mari F, Ariani F, Renieri A (2010) Novel FOXG1 mutations associated with the congenital variant of Rett syndrome. J Med Genet $47: 49-53$

Mondal S, Ivanchuk SM, Rutka JT, Boulianne GL (2007) Sloppy paired 1/2 regulate glial cell fates by inhibiting $\mathrm{Gcm}$ function. Glia 55:282-293.

Ohtsuka T, Sakamoto M, Guillemot F, Kageyama R (2001) Roles of the basic helix-loop-helix genes Hes1 and Hes5 in expansion of neural stem cells of the developing brain. J Biol Chem 276:30467-30474.

Ozen I, Galichet C, Watts C, Parras C, Guillemot F, Raineteau O (2007) Proliferating neuronal progenitors in the postnatal hippocampus transiently express the proneural gene Ngn2. Eur J Neurosci 25:2591-2603.

Pinto L, Götz M (2007) Radial glial cell heterogeneity-the source of diverse progeny in the CNS. Prog Neurobiol 83:2-23.

Pleasure SJ, Collins AE, Lowenstein DH (2000) Unique expression patterns of cell fate molecules delineate sequential stages of dentate gyrus development. J Neurosci 20:6095-6105.

Reznikov KY (1991) Cell proliferation and cytogenesis in the mouse hippocampus. Adv Anat Embryol Cell Biol 122:1-74.

Rice DS, Sheldon M, D'Arcangelo G, Nakajima K, Goldowitz D, Curran T (1998) Disabled-1 acts downstream of Reelin in a signaling pathway that controls laminar organization in the mammalian brain. Development 125:3719-3729.

Roybon L, Deierborg T, Brundin P, Li JY (2009) Involvement of Ngn2, Tbr and NeuroD proteins during postnatal olfactory bulb neurogenesis. Eur J Neurosci 29:232-243.

Sarthy V (2007) Focus on molecules: glial fibrillary acidic protein (GFAP). Exp Eye Res 84:381-382.

Shen L, Nam HS, Song P, Moore H, Anderson SA (2006) FoxG1 haploinsufficiency results in impaired neurogenesis in the postnatal hippocampus and contextual memory deficits. Hippocampus 16:875-890.

Sibbe M, Förster E, Basak O, Taylor V, Frotscher M (2009) Reelin and Notch1 cooperate in the development of the dentate gyrus. J Neurosci 29:8578-8585.

Soriano P (1999) Generalized lacZ expression with the ROSA26 Cre reporter strain. Nat Genet 21:70-71.

Steiner B, Kronenberg G, Jessberger S, Brandt MD, Reuter K, Kempermann G (2004) Differential regulation of gliogenesis in the context of adult hippocampal neurogenesis in mice. Glia 46:41-52.

Subramanian L, Sarkar A, Shetty AS, Muralidharan B, Padmanabhan H, Piper M, Monuki ES, Bach I, Gronostajski RM, Richards LJ, Tole S (2011) Transcription factor Lhx2 is necessary and sufficient to suppress astrogliogenesis and promote neurogenesis in the developing hippocampus. Proc Natl Acad Sci U S A 108:E265-E274.

Surget A, Tanti A, Leonardo ED, Laugeray A, Rainer Q, Touma C, Palme R, 
Griebel G, Ibarguen-Vargas Y, Hen R, Belzung C (2011) Antidepressants recruit new neurons to improve stress response regulation. Mol Psychiatry 16:1177-1188.

Tao W, Lai E (1992) Telencephalon-restricted expression of BF-1, a new member of the HNF-3/fork head gene family, in the developing rat brain. Neuron 8:957-966.

Thorgeirsson G, Robertson AL Jr, Cowan DH (1979) Migration of human vascular endothelial and smooth muscle cells. Lab Invest 41:51-62.

Van Dijck P, Gorwa MF, Lemaire K, Teunissen A, Versele M, Colombo S, Dumortier F, Ma P, Tanghe A, Loiez A, Thevelein JM (2000) Characterization of a new set of mutants deficient in fermentation-induced loss of stress resistance for use in frozen dough applications. Int J Food Microbiol $55: 187-192$

Vodovnik A (2003) Coexpression of S-100 and smooth muscle actin in nodular hidradenoma. Am J Dermatopathol 25:361-362.

Weiss KH, Johanssen C, Tielsch A, Herz J, Deller T, Frotscher M, Förster E (2003) Malformation of the radial glial scaffold in the dentate gyrus of reeler mice, scrambler mice, and ApoER2/VLDLR-deficient mice. J Comp Neurol 460:56-65.

Xuan S, Baptista CA, Balas G, Tao W, Soares VC, Lai E (1995) Winged helix transcription factor BF-1 is essential for the development of the cerebral hemispheres. Neuron 14:1141-1152.

Yao J, Lai E, Stifani S (2001) The winged-helix protein brain factor 1 interacts with groucho and hes proteins to repress transcription. Mol Cell Biol 21:1962-1972.

Zhang L, Luo XP (2011) Plasticity and metaplasticity of lateral perforant path in hippocampal dentate gyrus in a rat model of febrile seizure. Sheng Li Xue Bao 63:124-130.

Zhao S, Chai X, Frotscher M (2007) Balance between neurogenesis and gliogenesis in the adult hippocampus: role for reelin. Dev Neurosci 29:84-90

Zheng CH, Feng L (2006) Neuregulin regulates the formation of radial glial scaffold in hippocampal dentate gyrus of postnatal rats. J Cell Physiol 207:530-539. 